University of Tennessee Health Science Center UTHSC Digital Commons

\title{
The Association between Reading Comprehension and Prerequisite Skills for Children in Poverty
}

Hyo Jin Yoon

University of Tennessee Health Science Center

Follow this and additional works at: https://dc.uthsc.edu/dissertations

Part of the Speech and Hearing Science Commons

\section{Recommended Citation}

Yoon, Hyo Jin , "The Association between Reading Comprehension and Prerequisite Skills for Children in Poverty" (2011). Theses and Dissertations (ETD). Paper 309. http://dx.doi.org/10.21007/ etd.cghs.2011.0365.

This Dissertation is brought to you for free and open access by the College of Graduate Health Sciences at UTHSC Digital Commons. It has been accepted for inclusion in Theses and Dissertations (ETD) by an authorized administrator of UTHSC Digital Commons. For more information, please contact jwelch30@uthsc.edu. 


\title{
The Association between Reading Comprehension and Prerequisite Skills for Children in Poverty
}

\begin{abstract}
The purpose of this study was to investigate the relationship between reading comprehension and the prerequisite skills typically assessed by a school based speech pathologist with a focus on children raised in poverty. Based upon previous studies, three hypotheses were developed. First, children from low socioeconomic status (SES) backgrounds would not perform as well as children from the standardization sample on norm referenced language tests although the language tests would predict reading comprehension. Second, decoding would not be as good a predictor of reading comprehension for children from low SES backgrounds as it is in typically developing children from middle SES backgrounds because of differences in language ability. Third, processing dependent measures (working memory) would be more predictive of reading comprehension than nonverbal IQ testing for children from low SES backgrounds.
\end{abstract}

Twenty six children between the ages of 7 and 10 years of age participated in this study. All of the participants were from low SES homes, were receiving instruction in a mainstream classroom, and did not have an Individualized Education Program. None of the children had a history of hearing, visual, neurological, emotional or behavioral problems. All participants were tested to evaluate reading comprehension, word decoding, receptive vocabulary, receptive and expressive language, narrative skills, cognitive ability and working memory.

Children in this study performed significantly poorer than the standardization sample on all four language measures which included the Peabody Picture Vocabulary Test, 4th edition, the Clinical Evaluation of Language Fundamentals, 4th edition, the Narrative Scoring Scheme and Subordinate Index scores of the narrative task analyzed using the Systematic Analysis of Language Transcripts. Participants achieved similar scores on the Word Identification and Word Attack subtests of the Woodcock Reading Mastery Test, Revised, when compared to the standardization sample, while the average score on Passage Comprehension was below the expected mean. There were positive correlations between reading comprehension and decoding and language skills. Regression analyses showed that both decoding and language scores accounted for significant independent variance in reading comprehension beyond either decoding or language alone. In addition, all cognitive scores were significantly correlated with reading comprehension. Specifically, the word recall task of the Competing Language Processing Test explained a much higher proportion of the variance in Passage Comprehension than the Test of Nonverbal Intelligence, 3rd edition and the Nonword Repetition Task.

These results are consistent with previous studies that show that poverty or low SES has a negative effect on language skills and that children from low SES families are more likely to experience limited language and cognitive stimulation from the home environment. Results show that these children have smaller vocabulary sizes, less complex syntactic knowledge and less sophisticated knowledge of story structure than normative populations. However, they are able to able to decode within the normal range of ability. Hierarchical multiple regression analyses showed that language played a more important role in passage comprehension than shown in previous studies, indicating that their poor reading comprehension skills are likely due to weaknesses in language skills. Study results also support evidence that verbal working memory is associated with language and reading comprehension, demonstrating that both verbal working memory and reading comprehension require efficient allocation of limited resources for storage and processing. The results of this study suggest that language intervention should be initiated in an effort to improve reading comprehension for children in poverty. 


\section{Document Type \\ Dissertation \\ Degree Name \\ Doctor of Philosophy (PhD) \\ Program \\ Speech and Hearing Science}

\section{Research Advisor}

Ilsa Schwarz, Ph. D.

\section{Keywords}

decoding, language, narrative skills, poverty, reading comprehension, working memory

\section{Subject Categories}

Communication Sciences and Disorders | Medicine and Health Sciences | Speech and Hearing Science 


\title{
THE ASSOCIATION BETWEEN READING COMPREHENSION AND PREREQUISITE SKILLS FOR CHILDREN IN POVERTY
}

\author{
A Dissertation \\ Presented for \\ The Graduate Studies Council \\ The University of Tennessee \\ Health Science Center
}

In Partial Fulfillment

Of the Requirements for the Degree

Doctor of Philosophy

From The University of Tennessee

By

Hyo Jin Yoon

December 2011 
Copyright (C) 2011 by Hyo Jin Yoon. All rights reserved. 


\section{DEDICATION}

I would like to dedicate this dissertation to my parents, Mr. Jongdeok Yoon and Ms. Jungkyun Jeong who have instilled in me confidence and provided continual love and support throughout my life. 


\section{ACKNOWLEDGEMENTS}

I would like to thank my advisor and mentor, Dr. Ilsa Schwarz for taking me as her doctoral student and providing continued support, encouragement, and patience throughout my doctoral program. I appreciated the countless hours she devoted to helping me for five years. Without her guidance and help, my dissertation would not have been possible. I would like to thank my committee members, Dr. Mark Hedrick, Dr. Richard Allington, and Dr. Kristin King for providing invaluable suggestions, guidance, and assistance during completion of this dissertation. I would like to especially thank Dr. Hedrick for providing guidance and advice in both research and life as a Christian in general. I also express gratitude to my officemate and best friend, Lisa Bowers, for giving me lots of opportunities to experience "traditional American culture". I really appreciate her assistance with data collection, transcription and reliability. Without her help, I might still be looking for children to participate in my study. I would like to thank all the students that participated in this study and their parents. This study could not have been conducted without them.

I would like to thank my parents, families, and friends who provided endless love, support, and encouragement throughout this journey.

Finally, I would like to thank God for providing me the opportunity to work in this field, speech pathology. The strength, wisdom, and grace He gave guided my research throughout my doctoral program. 


\begin{abstract}
The purpose of this study was to investigate the relationship between reading comprehension and the prerequisite skills typically assessed by a school based speech pathologist with a focus on children raised in poverty. Based upon previous studies, three hypotheses were developed. First, children from low socioeconomic status (SES) backgrounds would not perform as well as children from the standardization sample on norm referenced language tests although the language tests would predict reading comprehension. Second, decoding would not be as good a predictor of reading comprehension for children from low SES backgrounds as it is in typically developing children from middle SES backgrounds because of differences in language ability. Third, processing dependent measures (working memory) would be more predictive of reading comprehension than nonverbal IQ testing for children from low SES backgrounds.
\end{abstract}

Twenty six children between the ages of 7 and 10 years of age participated in this study. All of the participants were from low SES homes, were receiving instruction in a mainstream classroom, and did not have an Individualized Education Program. None of the children had a history of hearing, visual, neurological, emotional or behavioral problems. All participants were tested to evaluate reading comprehension, word decoding, receptive vocabulary, receptive and expressive language, narrative skills, cognitive ability and working memory.

Children in this study performed significantly poorer than the standardization sample on all four language measures which included the Peabody Picture Vocabulary Test, 4th edition, the Clinical Evaluation of Language Fundamentals, 4th edition, the Narrative Scoring Scheme and Subordinate Index scores of the narrative task analyzed using the Systematic Analysis of Language Transcripts. Participants achieved similar scores on the Word Identification and Word Attack subtests of the Woodcock Reading Mastery Test, Revised, when compared to the standardization sample, while the average score on Passage Comprehension was below the expected mean. There were positive correlations between reading comprehension and decoding and language skills. Regression analyses showed that both decoding and language scores accounted for significant independent variance in reading comprehension beyond either decoding or language alone. In addition, all cognitive scores were significantly correlated with reading comprehension. Specifically, the word recall task of the Competing Language Processing Test explained a much higher proportion of the variance in Passage Comprehension than the Test of Nonverbal Intelligence, 3rd edition and the Nonword Repetition Task.

These results are consistent with previous studies that show that poverty or low SES has a negative effect on language skills and that children from low SES families are more likely to experience limited language and cognitive stimulation from the home environment. Results show that these children have smaller vocabulary sizes, less complex syntactic knowledge and less sophisticated knowledge of story structure than normative populations. However, they are able to able to decode within the normal range 
of ability. Hierarchical multiple regression analyses showed that language played a more important role in passage comprehension than shown in previous studies, indicating that their poor reading comprehension skills are likely due to weaknesses in language skills. Study results also support evidence that verbal working memory is associated with language and reading comprehension, demonstrating that both verbal working memory and reading comprehension require efficient allocation of limited resources for storage and processing. The results of this study suggest that language intervention should be initiated in an effort to improve reading comprehension for children in poverty. 


\section{TABLE OF CONTENTS}

CHAPTER 1. INTRODUCTION ....................................................................................1

Reading Comprehension, Decoding and Language Comprehension ............................

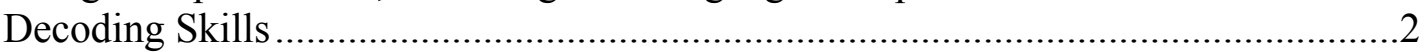

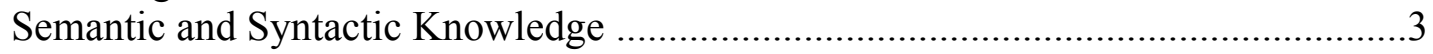

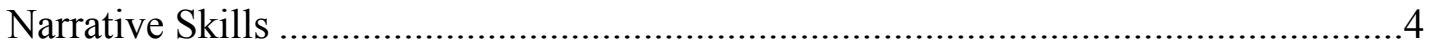

Reading Comprehension and Other Cognitive Factors ..........................................

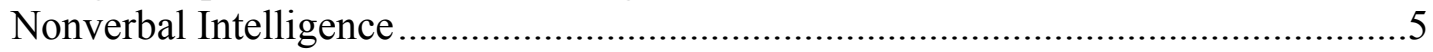

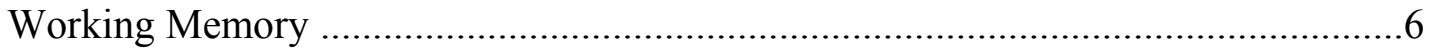

Children from Low SES Families....................................................................

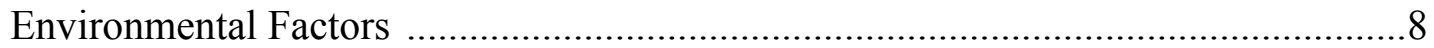

Language Skills of Children from Low SES Backgrounds ..................................10

Reading Skills of Children from Low SES Backgrounds .....................................12

Cognitie Skills of Children from Low SES Backgrounds ......................................13

Working Memory Skills of Children from Low SES Backgrounds ........................15

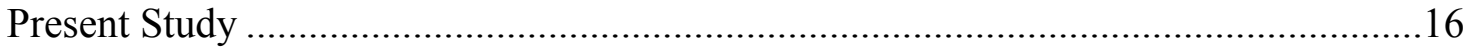

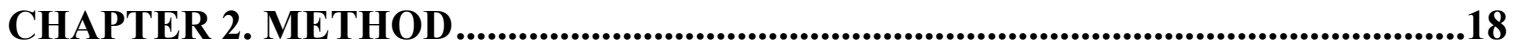

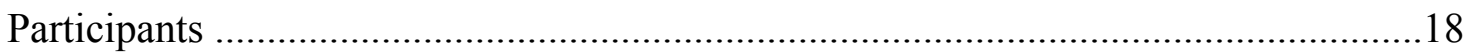

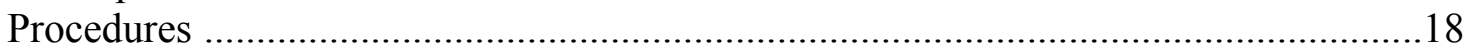

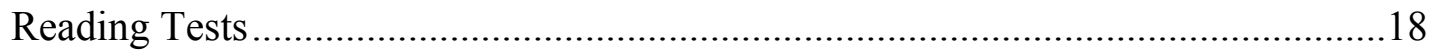

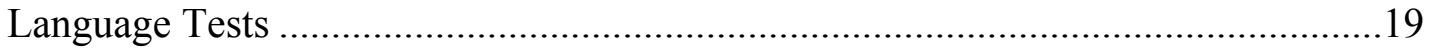

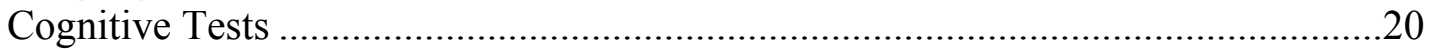

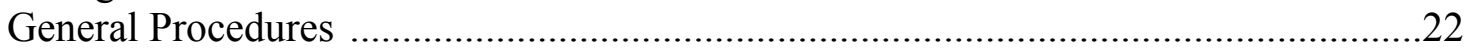

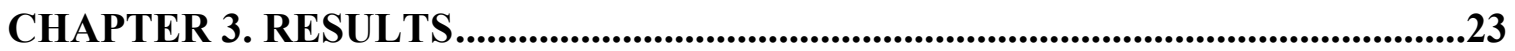

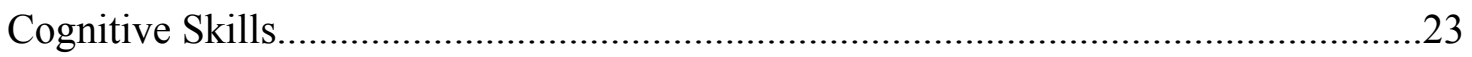

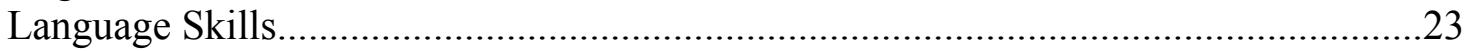

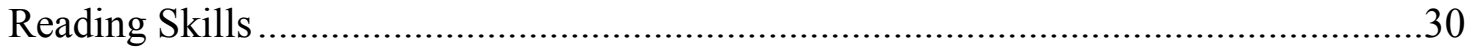

Working Memory Skills ............................................................................................30

The Relationship between Passage Comprehension, and Cognitive, Working

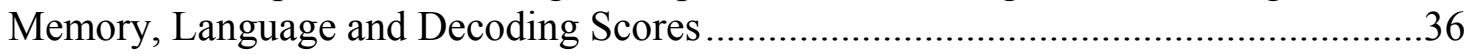

Processing Dependent Measures as Predictors of Reading Comprehension .................43

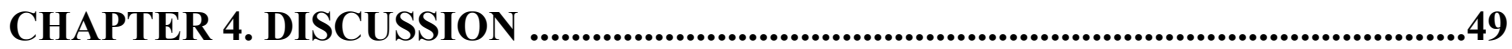

Langauge Skills and Reading Comprehension ...................................................49

Decoding Skills and Reading Comprehension .....................................................51

The Relationship between Reading Comprehension, Language and Decoding

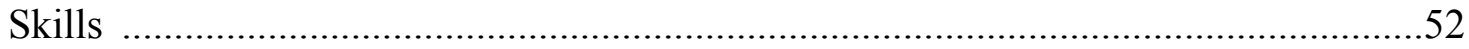

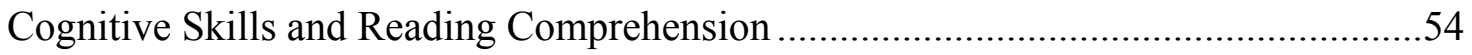

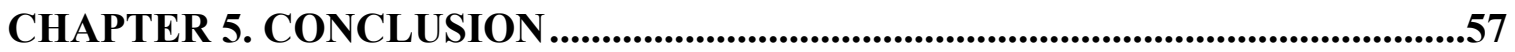


LIST OF REFERENCES..................................................................................................58

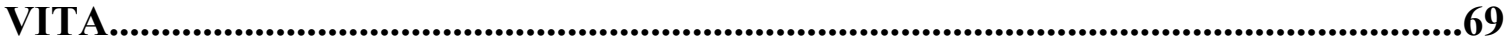




\section{LIST OF TABLES}

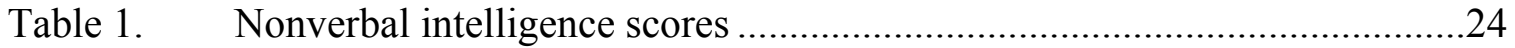

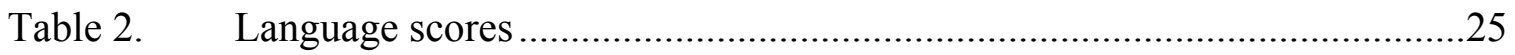

Table 3. Test performance by standard deviation on the language tests ..................29

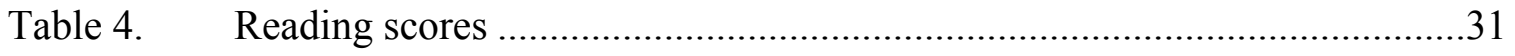

Table 5. NRT and CLPT scores using percentage of correct responses ...................32

Table 6. $\quad$ NRT and CLPT scores from this study and previous studies ....................33

Table 7. Correlations between Passage Comprehension and nonverbal intelligence, language, and decoding scores ...........................................37

Table 8. Partial correlations between Passage Comprehension and NRT, CLPT, NSS, and SI after controlling for age ....................................................38

Table 9. Hierarchical multiple regression analyses predicting Passage Comprehension using decoding and language scores.....

Table 10. Bivariate regression analyses predicting Passage Comprehension using TONI-3, NRT, and CLPT scores 


\section{LIST OF FIGURES}

Figure 1. Performance on the TONI-3

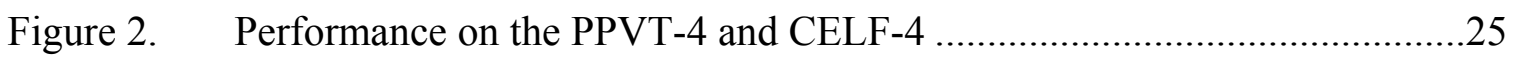

Figure 3. The average score of the NSS for this study and from the SALT database

Figure 4. The average score of the SI for this study and from the SALT database.....28

Figure 5. Test performance by standard deviation on the languag tests .....................29

Figure 6. Performance on the Word Identification, Word Attack, and Passage Comprehension subtests on the WRMT-R

Figure 7. Average percentages for the total number of phonemes recalled correctly on the NRT from this study and previous studies.....

Figure 8. Average percentages for the total number of words recalled correctly on the CLPT from this study and previous studies ............................................35

Figure 9. The relationship between Passage Comprehension and CELF-4 scores .....39

Figure 10. The relationship between Passage Comprehension and Word Identification scores

Figure 11. The relationship between Passage Comprehension and Word Attack scores

Figure 12. The relationship between Passage Comprehension and TONI-3 scores......44

Figure 13. The relationship between Passage Comprehension and NRT scores............45

Figure 14. The relationship between Passage Comprehension and the sentence comprehension of the CLPT scores

Figure 15. The relationship between Passage Comprehension and the word-reall task of the CLPT scores 


\section{CHAPTER 1. INTRODUCTION}

In 2009 , the U. S. government estimated that 43.6 million people, or roughly 14 percent of the population, had an income below the poverty threshold. Among the poor, children were disproportionately represented with 15.5 million or 20.7 percent under the age of 18 living in poverty (US Census Bureau Poverty, 2009). This statistic is important from an educational perspective. According to the 2009 National Assessment of Educational Progress report (NAEP, 2009), only half of fourth grade children eligible for free lunch or reduced-price lunch are able to read at or above basic level and among them, only 17 percent are able to read at or above proficient level. In contrast, 79 percent of children who are not eligible for free lunch or reduced-priced lunch are able to read at or above basic level and 45 percent are able to read at or above proficient level.

Research has demonstrated that poverty has a negative correlation with reading achievement (Cunningham, 2006). As the above statistics clearly indicate, there is a disparity between the reading achievement of children living in poverty and those from more affluent families. Children from low socioeconomic status (SES) families are more than twice as likely to perform more poorly in reading achievement. In addition, children from low SES families tend to lag behind children from more affluent families in academic achievement (Neuman, 2006).

When studying children reared in poverty, it is clear that multiple variables may have a negative influence on reading skills. As a result, it is often hard to find one specific cause of a reading problem or a direct relationship between poverty and reading comprehension. Empirical evidence has shown that SES and maternal education are highly related to reading development (Adams \& Ramey, 1980; Dollaghan et al., 1999). In addition, problems with reading comprehension may be associated with biological and environmental factors often found in low SES homes including single parent families, drug use during pregnancy, a negative medical history, and complications of labor and childbirth including low birth-weight and premature birth (Hooper et al., 1998; Sameroff et al., 1993; Stanton-Chapman et al., 2004).

\section{Reading Comprehension, Decoding and Language Comprehension}

Numerous studies have been conducted to examine the causes of reading comprehension problems among children from low SES backgrounds. In most cases, these studies have made comparisons between reading comprehension and those skills recognized as prerequisites to age-appropriate reading ability. In general, most agree that reading comprehension demands two different abilities. These are the ability to decode the written word and to understand what is written using sufficient language comprehension skills (Gough \& Tunmer, 1986; van Kleeck, 2007). Gough and Tunmer (1986) described the components of reading comprehension in the "Simple View of Reading". According to the Simple View of Reading, comprehension is comprised of decoding, and the subsets of decoding which are such variables as letter knowledge and 
print awareness. Language comprehension skills are made up of a subset of variables such as vocabulary and morphosyntactic knowledge. According to this model, reading equals the product of decoding and language comprehension, where each variable ranges from 0 to 1 (Gough \& Tunmer, 1986; Hoover \& Gough, 1990).

\section{Decoding Skills}

According to Gough and Tunmer (1986) and Hoover and Gough (1990), the goal of the beginning reader is to decode the word and access and retrieve the meaning from the lexicon. However, the goal of the skilled reader is to understand what is read. The association between isolated word reading or nonword reading and reading comprehension has been well documented (Catts et al., 2002; Parrila, Kirby \& McQuarrie, 2004; Shankweiler et al., 1990). Previous studies have reported that the association between decoding, language comprehension and reading comprehension changes with age, demonstrating that decoding skills tend to have greater impact on reading comprehension in the early grades, while language comprehension skills such as vocabulary and morphosyntactic knowledge appear to play a more important role in reading comprehension in middle and high school. In other words, in the early stages of learning to read, children will depend on decoding skills. Once they understand and are able to manipulate sound-letter correspondence, letter sequencing and spelling patterns, children read with automatic and fluent decoding. At this point, often referred to as the 'reading to learn' period, language comprehension skills become stronger predictors of reading comprehension.

The association between decoding and reading comprehension was investigated by Shankweiler et al. (1999). In their study with 361 children between 7.5 to 9.5 years of age, word and nonword reading skills were highly correlated with reading comprehension $(r=.79$ and $r=89$, respectively) and language comprehension was also related to reading comprehension $(r=.58)$. This finding confirmed that for children in the primary grades, decoding skills have a stronger association with reading comprehension than does language comprehension.

In a meta-analysis of studies that investigated decoding and reading comprehension, Gough, Hoover, and Peterson (1996) found that the average weighted correlations between decoding and reading comprehension were $.61, .53, .48$ and .39 for grades 1-2, grades 3-4, grades 5-6 and college, respectively. The average weighted correlates between language comprehension and reading comprehension were $.41, .50, .72$, and .68, for grades $1-2$, grades $3-4$, grades 5-6 and college, respectively. These results clearly show that the association between decoding and reading comprehension weakens with age and that the association between oral language skills and reading comprehension increases. 


\section{Semantic and Syntactic Knowledge}

A review of the literature on reading provides a number of studies that describe reading disorders caused by phonological deficits (Torgesen, 1996). While this link is clearly established, it seems to have overshadowed the importance of language ability for reading development. The results of the studies described in this section provide consistent evidence that limited language and cognitive input due to poverty will often lead to reading problems (Vellutino \& Flecher, 2005). Although decoding is critical to early literacy, reading comprehension has its roots in spoken language skills. Therefore, any weakness in spoken language comprehension is likely to have an impact on the development of reading comprehension. Reading comprehension requires both lowerorder language skills such as word recognition, identifying words, accessing the meaning of words at the word level, knowledge about syntactic structures at the sentence level, and higher-order skills such as the connection of sentences, making inferences to fill in missing information, integrating information, and understanding at the sentence level (Cain \& Oakhill, 2006; Kamhi, 2007; Roth, Speece, \& Cooper, 2002; van Kleeck, 2007).

The strong link between vocabulary and reading has been well documented. Previous studies have found that vocabulary is a significant predictor of decoding and reading comprehension for typically developing children as well as children with language impairment (Botting, Simzkin, \& Conti-Ramsen, 2006; Catts, Adolf, \& Weismer, 2006; Catts, Fey, Tomblin, \& Zhang, 2002; Muter, Hulme, Snowling, \& Stevenson, 2004; Ouelette, 2006; Roth et al., 2002; Seigneuric \& Ehrlich, 2005). In a study with typically developing fourth grade children, Ouellette (2006) examined how vocabulary and reading comprehension were associated. This study measured vocabulary breadth, assessing the number of known vocabulary words using receptive and expressive vocabulary tests, and vocabulary depth, assessing elaborated word knowledge using definition and synonym tests. Results showed that reading comprehension scores were correlated with receptive and expressive vocabulary tests and word definition ( $r=.461, r=.362$, and $r=.504$, respectively). In addition to these correlations, receptive vocabulary, expressive vocabulary, and depth of vocabulary knowledge scores accounted for 6.1, 4.2, and 12 percent of the variance in reading comprehension, respectively, after controlling for age, nonverbal IQ, and decoding.

Roth et al. (2002) examined the relationship between oral language and reading skills in a longitudinal study of 66 children from kindergarten through second grade. They found moderate to relatively high correlations between receptive vocabulary and word definition tests in kindergarten and reading comprehension in grade 1 , with $r=.38$ and .51 and those language tests in kindergarten and reading comprehension in grade 2 , with $r=.53$ and .70 , respectively.

Syntactic knowledge also is necessary for reading comprehension. Many studies have used syntactic awareness tasks in which a child is asked to judge, detect and change unacceptable sentences to assess understanding. Willows and Ryan (1986) examined the role of grammatical sensitivity through word reading and reading comprehension with children in first through third grades. The grammatical sensitivity task required a 
participant to respond to the incorrect word in each sentence and change the sentence with an appropriate word. Even after controlling for age and cognitive abilities, grammatical sensitivity accounted for seven percent of the variance in reading comprehension. In a related study, Cain (2007) examined the relationship between syntactic awareness and reading with 998 - and 10-year-old children. Two syntactic awareness tasks (grammatical corrections and word-order corrections) were administered. The correlation between word-order correction and reading comprehension for the younger group was $r=.403$ and between both word-order correction and grammatical correction and reading comprehension for the older group was $r=.275, r=.382$, respectively.

There are two studies in which morphological awareness was examined as a predictor of reading comprehension. Deacon and Kirby (2004) examined the contribution of morphological and phonological awareness to decoding and reading comprehension longitudinally with 143 second grade children. In their study, even after intelligence had been entered into the regression equation, morphological awareness at second grade still accounted for 8, 10 and 7 percent of the variance of reading comprehension at third, fourth, and fifth grade, respectively. Nagy, Berninger and Abbott (2006) found similar results with 607 students who were from fourth to ninth grade. In their study, participants were given morphological awareness tests including the suffix choice test and the morphological relatedness test. These morphological test scores were significantly correlated with reading comprehension. The correlation coefficients decreased from grade 4 - 5, grade 6-7 through grade $8-9$, yielding correlations of $r=.76, r=.65$, and $r=.59$, respectively.

\section{Narrative Skills}

Narrative skills demonstrate a higher order of language processing that requires the integration of linguistic, cognitive, and social skills (Norbury \& Bishop, 2003). This includes the ability to sequence events, to create a cohesive text through the use of explicit linguistic markers, to convey information, and to understand the cause-effect relationship (Paul et al., 1996).

Narrative skills share some of the same prerequisite abilities as reading comprehension (Roth et al., 2002; Westby, 1991). Westby (1991) suggested that narrative discourse plays an important role in the transition from oral language to written language since both narrative and written language have similar features in terms of concise syntactic style, rare and rich vocabulary, and decontexualized language. Success in both narrative discourse and reading comprehension requires lexical knowledge at the word level, syntactic and morphological knowledge at the sentence level, cohesive ability to connect sentence information, inferential ability to provide details not explicitly stated, and the ability to integrate information at the text level (Paul et al., 1996). Few studies have examined the direct relationship between narrative and reading comprehension skills. Snyder and Downey (1991) found that story retelling made a unique contribution to reading comprehension. Their study of predictors of reading comprehension included 
tests of phonological awareness, rapid naming, sentence completion, and narrative skills including story retelling, inferencing, and probe questions. They tested 93 typically developing children in early to middle grades (ages 8 to 11 years) and in middle to late elementary grades (11 to 14 years). For the older group, only the story retelling scores predicted reading comprehension.

Cain, Oakhill and Bryant (2004) examined the concurrent relationship between knowledge of story structure and reading comprehension with 102 children at 8,9 and 11 years of age. A story anagram task was used to have a child arrange sentences in correct order. The number of sentences given to children varied according to their ages. The results showed significant correlations between reading comprehension and story anagram scores at all age groups, $r=.402$ ( 8 years), $r=.344$ (9 years), and $r=.299$ (11 years). In the multiple regression analysis, after controlling for verbal IQ, vocabulary, word reading and working memory, the story anagram score still accounted for a portion of the variance in reading comprehension at 11 years of age. In a related literature review by Oakhill and Cain (2006), story structure understanding was shown to be a strong predictor of reading comprehension beyond the contribution of vocabulary and verbal IQ (for a review, see Oakhill \& Cain, 2006).

In a related investigation, Klecan-Aker and Caraway (1997) investigated the relationship between narrative skills and reading achievement with 80 fourth-grade and sixth-grade African-American children. The authors measured the participants' SES levels using The Four Factor Index of Social Status (FFIS, Hollingshead, 1975). The average SES level was 40 which means participants were mostly from middle SES homes. The authors found that story grammar and syntactic complexity were correlated with reading comprehension, with $r=.37$ and $r=.33$, respectively. As a result of this study and related investigations, it is evident that knowledge of story structure and the use of complex sentences have associations with reading comprehension both concurrently and longitudinally.

\section{Reading Comprehension and Other Cognitive Factors}

\section{Nonverbal Intelligence}

In addition to the language skills known to be associated with reading comprehension, a longitudinal study by Catts et al. (2002) explored the relationship between oral language, cognitive factors, and reading outcomes for 570 children with language impairment from preschool through fourth grade. They used multiple regression analyses to examine predictors of word decoding and reading comprehension and found that nonverbal intelligence at kindergarten was the third strongest predictor of reading comprehension at second grade and the second strongest predictor of reading comprehension at fourth grade. 
Alloway and Alloway (2010) investigated intelligence and working memory as predictors of literacy skills including decoding, reading comprehension and spelling. Ninety eight participants were tested at 5 years of age and retested six years later. Working memory at 5 years of age was the best predictor of literacy skills. At the age of 10 , intelligence explained an additional proportion of the variance in literacy skills.

\section{Working Memory}

There is evidence that working memory is associated with reading comprehension (Cain et al., 2004; Nation, Adams, Bowyer-Crane, \& Snowling, 1999). According to the working memory model by Baddeley $(1986,1998)$, working memory is multi-component cognitive system that involves a central executive system, phonological loop, visuospatial sketchpad, and episodic buffer. The phonological loop, also referred to as phonological short term memory, is considered to play an essential role when learning new words because it allows a child to form a stable phonological representation before adding it to their lexicon. In addition, the phonological loop has a relationship with short-term memory because both involve temporary storage of information. The phonological loop typically has been measured using digit-span, word span, or nonword repetition tasks.

A different model of working memory, described as functional working memory, was developed by Just and Carpenter (1992). This model presents a theoretical model of storage and processing functions in working memory for language comprehension. Storage is responsible for the temporary retention of verbal input already processed while processing refers to the language processing of various verbal inputs. It is a computational model in which both storage and processing functions of working memory during comprehension share the same amount of resources from the total amount of working memory capacity. In other words, the resources for the storage and processing functions of working memory must be allocated effectively for language comprehension. If most resources for working memory capacity are allocated to processing, there will be only limited resources available for storage. The differences found in language comprehension across individuals may be due to an inefficient regulation of working memory functions as well as working memory capacity. Studies have shown that people with poor comprehension tend to use the majority of working memory capacity for processing. The limited allocation of resources for storage then forces the person to forget previous information in storage (Daneman \& Carpenter, 1983; Montgomery, 2002).

Reading comprehension also requires the allocation of working memory resources for storage and processing. Regardless of the model used, there is evidence that working memory plays a role in reading comprehension. In particular, children with reading comprehension problems are likely to display working memory deficits (Cain, 2006; Nation et al., 1999; Pimperton \& Nation, 2010; Swanson, 1999).

Goff, Pratt and Ong (2005) investigated language, decoding, and working memory as predictors of reading comprehension with 180 typically developing children in third grade through fifth grade. They questioned whether working memory predicts 
reading comprehension beyond decoding and language skills. They found that after age, general intelligence, and decoding were entered, language variables accounted for an additional 9 percent of the variance for reading comprehension, and memory tasks contributed 2 percent of the variance for reading comprehension. Of the working memory tasks, short-term visuospatial memory tasks that required participants to touch blocks that lit up in the same order, and verbal learning and retrieval which required participants to remember lists of words in any order, contributed independently to reading comprehension after controlling for age, intelligence, decoding and language skills. The authors interpreted these results to indicate that verbal learning and retrieval are required to retain information for a short time, demonstrating how this skill may be related to reading comprehension.

Cain, Oakhill, and Bryant (2004) attempted to shed light on the role of working memory in reading comprehension with 102 children who were 8, 9 and 11 years of age. First, they controlled for well-known factors that influence reading comprehension (i.e. word decoding, verbal intelligence, receptive vocabulary). After controlling for these factors, they found that working memory tested using sentence-span and digit span tasks still accounted for reading comprehension for all three groups. Specifically, they reported a sentence-span task had a stronger relationship with reading comprehension than a digit span task. These results indicate that the relationship between working memory tasks and reading comprehension tends to be stronger when the test stimuli are verbal rather than digital or visuospatial.

Several researchers have shown that different aspects of working memory skills are likely to have an association with different reading skills (Cain, 2006; Nation et al., 1999; Oakhill, Yuill \& Parkin, 1986). Phonological working memory has strong link with decoding skills while tasks that tap simultaneous storage and working memory have a strong relationship with reading comprehension. These findings have been reported in the studies for children with reading comprehension. Nation et al. (1999) used three experiments to compare the working memory skills of 14 children who had reading comprehension difficulties but no deficit in decoding skills with 15 typically developing children who had adequate decoding and reading comprehension skills. In the first experiment, participants were asked to recall short and long words and nonwords. The results showed that children with reading comprehension problems performed as well as the control group on the word and nonword repetition tasks. In the second experiment, the authors examined whether semantic skills influenced word recall abilities and compared the two groups' word recall skills on concrete and abstract words. The children with poor comprehension scored lower than the typically developing children on vocabulary knowledge. Overall, the results showed that children with poor reading comprehension were less able to recall abstract words but were no different than the controls in the ability to recall concrete words. In the last experiment of their study, children were given two memory span tasks that required simultaneous storage and processing of verbal and spatial stimuli. In the listening span task, children were asked to state whether a sentence was true or false and then recall the last words from each sentence in sets of varying in length. In the spatial span task, children were asked to state the location of a rectangle in an array of one rectangle and the three squares and then find 
the odd shape in a set of three shapes. The children with reading comprehension problems showed deficits on only the verbal working memory task.

Results from working memory tasks similar to those reported by Nation et al. (1999) were obtained by Cain (2006). In her study, thirteen children with poor reading comprehension and no decoding problems were paired with thirteen age-matched typically developing peers. However, in her study, the two groups were also matched for vocabulary knowledge. The results showed that children with poor comprehension were able to recall words regardless of their concreteness or abstractness. Results of this investigation indicate that children who have difficulties in reading comprehension with adequate decoding skills appear to have typically developing phonological working memory skills. However, they demonstrate salient deficits when they are asked to hold and process verbal information simultaneously.

Repeated studies have documented that working memory contributes to reading comprehension beyond the contribution of IQ, language and decoding skills. That is, the ability to hold and process information is associated with reading comprehension skills because understanding written material requires the ability to access the lexicon, retrieve meaning, retain information, process sentences, and integrate information from a sentence or a whole passage.

\section{Children from Low SES Families}

Many studies have shown that children reared in poverty display difficulty in spoken and written language (Burt, Holm, \& Dodd, 1999; Hart \& Risley, 1995; Pruitt \& Oetting, 2009; Pruitt, Oetting, \& Hegarty, 2010; Terry et al., 2010; Whitehurst, 1997; Whitehurst \& Fischel, 2000). Specifically, children from low SES backgrounds tend to show poor oral language skills. However, the characteristics of their language skills as well as their cognitive profile will often differ from children diagnosed with language impairment. In general, there is evidence that children reared in poverty are more likely to have language delays affected by environmental factors. In contrast, children with language impairments show language deficits even though they are surrounded by appropriate language input and cognitive stimulation (Ginsborg, 2006; Hart \& Risley, 1995; Leonard, 1998; Pruitt \& Oetting, 2009).

\section{Environmental Factors}

Reduced cognitive stimulation, less parental involvement in academics, a limited home literacy environment represented by the absence of books, limited shared-book reading with parents, and low expectations for academic achievement with children from low SES backgrounds may lead to difficulty with reading (Bhattacharya, 2010; Eamon, 2002; Hecht, 2001). Children reared in poverty are also likely to have cumulative risk factors rather than one risk factor. In a study by Stanton-Chapman et al. (2004) that included 3-year-old participants from low-income families $(\mathrm{N}=853), 94$ percent of the 
children had at least one risk factor and 39 percent were exposed to three or more risk factors. Results found that as the number of risk variables increased, language performance measured by Preschool Language Scale-3 (PLS-3; Zimmerman, Steiner, \& Pond, 1992) decreased.

Parental education, specifically maternal educational level is known to influence child language development (Adams \& Ramey, 1980; Dollaghan et al., 1999). For example, Dollaghan et al. (1999) examined the relationship between maternal education and early language development with 3-year-old children. After adjusting for ethnicity, the effect of maternal education was found in language outcomes. Results reported that mean length of utterance in morphemes (MLUm), the number of different words (NDW), and total number of words (TNW) differed across three groups that were categorized by maternal education levels: did not graduate from high school, high school graduate, and college graduate. Children whose mothers did not graduate from high school did not differ from those who mothers did graduate from high school in MLUm, NDW, and TNW. Differences were found between these two groups and the children whose mothers graduated from college. On the Peabody Picture Vocabulary Test-Revised (PPVT-R; Dunn \& Dunn, 1981), a receptive vocabulary test, the three groups did differ. Children whose mother had a college degree performed the best, followed by those whose mothers graduated from high school. Those with mothers who did not graduate from high school scored the lowest on the PPVT-R.

Given the often limited education of mothers from low SES families, conversational or interactional style has been studied to determine if differences exist between mothers or caregivers and their children from low and middle to high SES backgrounds. The results indicate that mothers from low SES backgrounds are more likely to use short and imperative sentences, ask fewer questions, and respond less often to their children than middle to high SES background (Adams \& Ramey, 1980; Hart \& Risley, 1995; Hoff-Ginsberg, 1991; Wulbert, Inglis, Kriegsman, \& Mills, 1978).

In addition to mother's educational level, other socio-economic variables influence children's spoken and written language. A study by Molfese, Modglin, and Molfese (2003) examined the role of SES and Home Environment on reading development in a longitudinal study of children ages 3 through 8 to 10. They used an SES factor that included parent education, parental occupation, and family income and a Home Environment factor using educational resources, parental involvement, and parenting practices. In this study, participants were administered reading tasks at 8 to 10 years of age. They found that the combination of these factors accounted for a greater percentage of the variance in reading scores at the ages of 8 to 10 than a singular one did. One particularly interesting finding from this study was that early Home Environment factors measured at age 3 predicted reading achievement at ages 8-10 better than Home Environmental factors measured at ages 8-10. This study shows that the early home environment and SES play an important role in later reading achievement.

Other studies have explored the public literacy environment with children raised in poverty. An ecological study by Newman and Celano (2001) compared the print 
environments of two middle income and two low income neighborhoods. They compared the number of places to find reading materials, the quantity and quality of signage, the quality of public places for reading, availability, quantity, and accessibility of preschools, the quantity and quality of books and computers, the quality of librarians, and availability to an in-school library. Results indicated that differences between middle and low income neighborhoods were striking in terms of all resources. Children living in the two middleincome communities were more likely to have more places to find books, more signs in good condition, more public places to read books and observe people who were reading, and more books and a better selection of book collections, more trained and experienced librarians and more days when a library was open in local preschool and school libraries. For example, in the places children find books, children from the two middle-income communities could access 13 titles per every one child in one community and one book title for every three children in the other, while children from the two low-income communities could access one title per every 20 children in one community and 300 per child in the other. Even in school libraries, the middle-income communities had 18.9 to 25.7 books in good to excellent condition per child, while those in low-income communities had 10.6 to 12.9 books in poor to good condition per child with no books in good to excellent condition.

The consequence of different levels of exposure to print in home and public environments may create different opportunities for learning to read for children from middle and low SES backgrounds. Children who access literacy environments easily and frequently are more likely to achieve better reading scores. Conversely, children who receive less exposure to print in either home or public environments may develop reading more slowly or fail to achieve good reading comprehension.

\section{Language Skills of Children from Low SES Backgrounds}

There is considerable evidence that children from low SES families perform significantly poorer on vocabulary (Dollaghan et al., 1999; Horton-Ikard \& Ellis Weismer, 2007; Whitehurst, 1997), grammar (Dollaghan et al., 1999), narrative skills (Myers \& Botting, 2008; Peterson, 1994; Shiro, 2003; Whitehurst, 1997), phonological

awareness (Burt et al., 1999) and general receptive and expressive language skills (Locke, Ginsborg, \& Peers, 2002) when compared to their middle to high SES age peers.

A study by Horton-Ikard and Ellis Weismer (2007) investigated vocabulary and word learning with 30- to 40- month-old African-American toddlers from low and middle SES families. They found that children from low SES families scored lower than the middle SES families on standardized receptive and expressive language tests and spontaneous speech samples. In a similar study, Pruitt and Oetting (2009) investigated morphological skills using past tense marking with six-year-old African-American children from low and middle SES backgrounds. Even though they found that children from low SES backgrounds scored more than one standard deviation below the mean on the syntax subtests of the Test of Language Development-Primary, Third Edition (TOLDP: 3, Hammill \& Newcomer, 1997) as well as on the Peabody Picture Vocabulary Test 
(PPVT-III; Dunn \& Dunn, 1997), they did not differ on the use of past tense marking when compared to those from middle SES backgrounds.

In a study by Whitehurst (1997), 594 children from 3 to 6 years of age who were raised in poverty were administered a battery of language tests including the PPVT-R for receptive vocabulary, the Expressive One Word Picture Vocabulary Test and Expressive One Word Picture Vocabulary Test-Revised (EOWPVT; Gardner, 1981, 1990), for expressive vocabulary, Mean Length of Utterance (MLU), the total number of complex sentences using narrative samples, and the Word Structure subtest from the Clinical Evaluation of Language Fundamentals-Preschool (CELF-P; Wiig, Secord, \& Semel, 1992). In this study, children who were 3,4 , and 5 years old had an average performance that fell below one standard deviation of the mean on the vocabulary test. Approximately 85 percent of the children scored below average on the receptive and expressive vocabulary tests. However, on the three syntax tests, the 4- and 5-year-old groups' means except for MLU of the children at 5 years fell within the average range.

In a similar study, Locke et al. (2002) explored the language development of 240 three to four year-old children reared in poverty in the UK. They found that more than 50 percent of children in poverty scored one standard deviation below the mean on the CELF-P ${ }^{\mathrm{UK}}$, while they obtained average scores on a general cognitive test, The British Ability Scales II Early Years (BAS II).

Studies have shown that poverty may also contribute to the lower performance of children from low SES homes when tested on narrative skills. For example, Shiro (2003) examined narrative skills using fictional and personal narratives with 113 first and fourth graders from high and low SES backgrounds in Venezuelan. On the fictional narrative task, children from high SES backgrounds performed better; however, a similar performance from both groups was found when using personal narratives. In the study cited previously by Whitehurst (1997), 4 to 5 year-old children were also asked to retell a story using the Renfrew Bus Story (Cowley \& Glasgow, 1994) which is norm-referenced. Results showed they scored roughly one standard deviation below the mean on the Renfrew Bus Story.

A study of the language skills of school-aged children reared in poverty in the UK was conducted by Myers and Botting (2008). They examined the language skills of 36 11-year olds using the British Vocabulary Scales (BVS; Dunn et al., 1997), the Test of for Reception of Grammar-2, (TROG-2; Bishop, 2003), and Recall of Narrative Instrument (Bishop, 2004). Results showed that children from low SES backgrounds differed from the test standardization sample on immediate narrative story retelling, with an average standard score of $93.4(t=-2.471, p=.019)$ while they did not differ on narrative recall within 30 minutes, with an average score of $95.1(t=-2.016, p=.052)$.

In summary, children from low SES homes are more likely to show weaknesses in language skills from preschool through school age. Even though research has demonstrated that there is no single direct causal relationship between poverty and language disorders, various environmental and biological factors appear to have a 
negative effect on language development for children who are raised in poverty. These language problems appear to accumulate and result in reading problems in school (Terry et al., 2010; Whitehurst \& Fischel, 2000).

\section{Reading Skills of Children from Low SES Backgrounds}

According to reading studies, half of the number of children from low SES backgrounds fails to read at the basic level. The home environment associated with poverty and an insufficient literacy environment in the community may have a reciprocal relationship, influencing oral language development and in turn, reading development. Research evidence indicates that children who live in poverty perform below the national average on preliteracy skills including print awareness, letter knowledge and phonological awareness, all of which play critical roles in reading development (Barone, 2006; Dodd \& Carr, 2003; Justice \& Ezell, 2001). Mothers with a limited educational background may not provide an optimal reading environment that includes activities such as shared book reading, access to books, and frequent activities with books. When children have only limited experiences with literacy before they begin preschool or kindergarten, they are more likely to experience reading failure in school.

Lonigan et al. (1999) investigated the emergent literacy skills of preschool-age children from low and middle SES backgrounds and found that the children from low SES backgrounds showed poorer performance on emergent literacy tasks including letter name knowledge and concepts about print. A similar study conducted by Dodd and Carr (2003) with 83 children ranging from 4:11 to 6:4 in age from low and high SES backgrounds noted that the children from high SES homes performed better on letter production, letter-sound recall, and letter-sound recognition than those from low SES homes.

In a study of phonological awareness skills with children ranging between 46 to 58 months of age from low and high SES families, Burt, Holm, and Dodd (1999) reported that the children from low SES families performed poorer than those from high SES families on all tasks including alliteration, rhyme awareness, phoneme isolation, phoneme segmentation, and syllable segmentation.

In general, early literacy studies demonstrate that children who are raised in poverty face emergent literacy problems that are likely to grow into academic difficulties with reading acquisition. There is evidence that reading problems in the early school years grow into reading failure, with a gap between the children from low SES homes and the average to above average reader (Catts, Bridges, Little, \& Tomblin, 2008; Francis, Shaywitz, Stuebing, Shaywitz, \& Flecher, 1996).

Studies of literacy development with school-age children are consistent with those of younger children. Duncan and Seymour (2000) examined emergent literacy and decoding skills with 1624 to 7 year old children from high and low SES families. Performance on letter knowledge and decoding including word reading and nonword 
reading differed in favor of children from high SES families. In a study examining the extent to which duration of poverty has an impact on reading development, Najman et al. (2009) administered the word decoding task from the Wide Range Achievement Test (WRAT) to children who were exposed to poverty on a scale from never to several periods across 14 years. They found that children who were exposed to poverty only one time scored below average on the WRAT, and as the frequency of experiences with poverty increased, the mean score on the WRAT decreased from 101.53 (never experienced poverty) to 96.40 (experienced poverty 3 to 4 times).

Myers and Botting (2008) explored the reading and oral language skills of 11year-old children reared in poverty. Children from low SES homes performed below the average on standardized reading tests, with 58 percent of the children falling below 1 standard deviation from the mean on one or more of the reading tests. Among the total participants, 28 percent scored below 1 standard deviation from the mean on the word decoding and reading comprehension tests and 11 percent scored below 1 standard deviation from the mean on decoding alone. However, in this study, 50 percent of the children were enrolled in special education, and 19 percent received extra support from school. When considering the characteristics of this population, the poor performance on reading tasks may be, at least in part, attributed to cognitive deficits rather than solely environmental factors.

Hacht and Greenfield (2002) investigated the reading skills of 170 children from low income homes in first grade and in third grade. Results showed that children living in poverty obtained an average standard score of 84.3 and 85.5 on the Letter-Word Identification subtests of the Woodcock-Johnson Test of Achievement-Revised (WJTA-R) in first and third grades, respectively, and 85.5 and 88.7 on the Passage Comprehension subtest from the WJTA-R in first and third grades, respectively. Children reared in poverty also experienced more difficulty with vocabulary when compared to their reading skills, with average standard scores of 78.4 and 76.5 on the Peabody Picture Vocabulary Test-Revised (PPVT-R; Dunn \& Dunn, 1981) in first and third grades, respectively.

\section{Cognitive Skills of Children from Low SES Backgrounds}

Issues related to cognitive development associated with poverty have been well documented (Barajas et al., 2008; Brooks-Gunn \& Duncan, 1997; Korenman, Miller, \& Sjaastad, 1995; Najman et al., 2009; Sirin, 2006; Washington, 2001). Research has shown that even after controlling for maternal education level, and maternal IQ, family income influences both cognitive and academic achievement.

Duncan, Brooks-Gunn, and Klebanov (1994) conducted a longitudinal study supported by the Infant Health and Developmental Project (IHDP) to examine cognitive and language abilities of children in poverty. As part of this project, they investigated the association between poverty and intelligence with children who were 5 years of age. Poverty was categorized according to the duration of poverty: persistent poor, episodic poor and never poor. Cognitive outcome was measured by the Wechsler Preschool and 
Primary Scale of Intelligence (WPPSI, Wechsler, 1967), with scores for verbal IQ, performance IQ, and full scale of IQ. They found that children from persistent poverty scored an average 9 points lower than those whose families never experienced poverty even after controlling for factors such as maternal education, and maternal IQ. Furthermore, even among children who experience poverty persistently or episodically, children who experienced persistent poverty scored an average 4 points lower than those who experience poverty for some period in their life on IQ test.

In a similar study by Najman et al. (2009) the effect of duration of poverty on cognitive development was examined. The authors followed children from pregnancy to 14 years of age and counted the frequency of exposure to poverty. At the beginning of the study, a total 7223 pregnant women participated. This total dropped to 3799 participants (53\% of the original pool) when children were evaluated at 14 years of age. Family income was used as the SES indicator and was obtained at the child's birth, 6 months, 5 years, and 14 years of age. Cognitive outcome was measured using the Raven's Standard Progressive Matrices (Raven, 1989). Results showed that children from low income homes differed significantly from those who were never poor at all stages. Children from low income homes obtained scores ranging from 96 to 98 whereas children who never experienced poverty obtained scores ranging from 101.20 to 101.51. Additionally, the more frequently a child experienced poverty, the lower the score on the Raven's test with a reduction of 2.19 points for every additional poverty experience. This finding suggests that persistent poverty is detrimental to cognitive development.

Studies have also found that poverty influences children's cognitive growth and development (Bradley \& Corwyn, 2002; Hackman \& Farah, 2009; NICHD, 2005). These studies show that children from low SES families are more likely to lack cognitive stimulation, adequate nutrition, medical care, access to learning materials, spend less time with parents, and experience low quality care and educational facilities. As a result, even though they may seem to catch up to their peers from middle to high SES families on basic letter knowledge at the entry to kindergarten because of educational support of school, the gap between word knowledge, reading, and academic achievement tends to widen (Denton, West \& Watson, 2003).

Turkheimer et al. (2003) examined the role of genetics and environment on the intelligence of 7 year-old children who were from low and middle to high SES backgrounds. The authors analyzed data from the National Collaborative Perinatal Project that included 59,397 children as participants. They found that environment accounted for the greatest proportion of the variance in the intelligence of children from low SES backgrounds. Conversely, genetics better explained intelligence in children from middle to high SES backgrounds. It may be that environmental factors are more likely to influence the cognitive development of children reared in poverty, while for children who receive sufficient cognitive stimulation from their environment, genetics appears to influence intelligence.

In 1996, Fazio, Naremore, and Connell (1996) examined the development of language and cognitive skills with 34 children from low income homes. In a longitudinal 
study from kindergarten to second grade, participants were divided into three groups according to language and cognitive skills: children with a language problem alone, children with language and cognitive problems, and children with typical development. All participants were administered a nonverbal cognitive test as measured by the Columbia Mental Maturity Scale (CMMS, Burgeister, Blum, \& Lorge, 1972) at kindergarten and second grade. The nonverbal cognitive abilities of all three groups improved from kindergarten through second grade. Specifically, the group of children with language and cognitive problems obtained a mean score of 75.80 ranging from 7084 on the CMMS test at kindergarten. This group's mean score improved to 94.10 by second grade. This score fell within one standard deviation from the mean even though it was still below the mean. The mean scores for the other two groups on the CMMS also improved from 91.33 to 100.83 for children with language problems only, and from 98.93 to 110.83 for children with typical development. The authors explained that children raised in poverty are likely to show disadvantages on cognitive development measures due to limited experience. However, as a result of formal instruction in school, cognitive development may be enhanced and result in improved test scores.

The literature indicates that cognitive skills are related to reading comprehension. Studies of children with language impairment show clear evidence that intelligence, usually measured through nonverbal intelligence tests, predicts reading comprehension with moderate to high correlations (Catts et al., 2002, 2006). Children from low SES backgrounds tend to show below average scores on standardized intelligence tests, although they fall within normal range. Furthermore, several studies provide evidence that children from low SES backgrounds do not differ from those from middle to high SES backgrounds on working memory tasks which are strongly related to the ability to learn language.

\section{Working Memory Skills of Children from Low SES Backgrounds}

Studies have shown that children from low SES families are more likely to be over-identified as having a language or learning disorder when assessed by standardized tests (Roseberry-McKibbin, 2008). Campbell et al. (1997) suggested that processingdependent measures such as the Nonword Repetition Task (NRT) or Competing Language Processing Task (CLPT) may serve as an alternative means to assess the language abilities of children from linguistically and culturally diversity groups and low SES backgrounds. These processing-dependent measures are not as reliant upon prior knowledge and may differentiate children with language impairment from typically developing children (Laing \& Kamhi, 2003).

Few studies have investigated the working memory skills of children from low SES homes. Engel, Santos and Gathercole (2008) explored working memory and language skills with 40 6- to 7-year-old children from low SES and high SES backgrounds. This study provided clear evidence that the two groups showed a similar performance on working memory tasks even though the children from low SES backgrounds obtained significantly lower scores on expressive and receptive vocabulary 
tests. In contrast, some researchers have found that children from low SES backgrounds also have delayed development in working memory when measured by digit span or nonword repetition. In a study by Burt et al. (1999), 57 participants from low and uppermiddle SES homes who ranged in age from 46 to 58 months were administered the Nonword Repetition Task. Children from low SES backgrounds obtained significantly lower scores than those from high SES backgrounds.

The suggestion that processing-dependent measures do not depend on prior knowledge was also explored in studies that investigated the working memory skills in linguistically and culturally diverse groups. Campbell et al. (1997) investigated whether processing-dependent measures including the NRT and CLPT might provide an unbiased measure of processing with 158 boys ranging from 11 to 14 years of age from both cultural majority and minority homes. They found that the participants did not show differences on processing-dependent measures, even though the cultural majority children outperformed the cultural minority children on knowledge-dependent measures including the Oral Language Scale from the Woodcock Language Proficiency Battery-Revised (Woodcock, 1991).

In a related study, Rodekohr and Haynes (2001) examined working memory skills using the NRT and CLPT and language ability using a standardized test of expressive and receptive language, the TOLD-2P, with 40 African-American and White children. The mean age of the participants was 7 years and 2 months. In this study, results indicated that there were no significant differences on the two working memory tasks between the groups while the typically developing White children obtained significantly higher scores than typically developing African-American children on the standardized language test.

As a result of studies with children from differing SES or cultural backgrounds, it remains unclear whether typically developing children from low SES homes are comparable to their peers from middle to high SES families on working memory tasks using the NRT and/or the CLPT. However, most investigations have found that processing tasks do not show a bias against children from poor or minority backgrounds.

\section{Present Study}

A large number of studies have explored various predictors or correlates of reading comprehension with children from low SES homes. However, there have been very few studies that have investigated those factors that are likely to be assessed by a school speech-language pathologist. Little is known about the relationship between reading comprehension and the known language, decoding, cognitive and processing correlates of reading ability with school-aged children from low SES families.

In particular, no studies have investigated how strengths or weaknesses in these skill areas might differentially affect reading comprehension. For this reason, this study investigated the relationship between reading comprehension and 1) decoding skills, 2) 
receptive and expressive language skills including narrative ability, 3) cognitive skills, and 4) working memory with children from low SES backgrounds.

As a result, it is hoped that this investigation might assist school based speechlanguage pathologists in deciding what assessments to use when testing children from low SES homes and how the results of these assessments might assist in the design of interventions for reading comprehension.

Based upon the results of previous studies that investigated reading development with children from a variety of SES backgrounds, the following three hypotheses were developed,

(1) Children from low SES backgrounds would not perform as well on standardized tests of language as the children from the test standardization sample. However, language skills will show a strong relationship with reading comprehension.

(2) Decoding ability would not be as good a predictor of reading comprehension for children from low SES backgrounds as it is for typically developing children from middle SES backgrounds because of differences in language abilities.

(3) Processing-dependent measures (working memory) would be predictive of reading comprehension with children from low SES backgrounds and will contribute more to reading comprehension than nonverbal IQ. 


\section{CHAPTER 2. METHOD}

\section{Participants}

Twenty-six children (11 boys and 15 girls) between the ages of 7 and 10 years of age participated in this study $(M=9.0, S D=10.7)$. The children were all enrolled in the same elementary school and participated in an after school program called SOAR, from which they were recruited. The school that these children attended was a public school in Knoxville, TN where 69 percent of the students were eligible for the free lunch or reduced-price lunch program, 47 percent of the students were African-American, 28 percent of the students were Hispanic and 25 percent of the students were Caucasian.

All of the participants met several inclusion criteria. First, all participants were from low socio-economic status (SES) homes. Determination of low SES was based on their participation in the free or reduced-price lunch program at school. Second, all participants were receiving instruction in a mainstream classroom and did not have an Individualized Education Program (IEP). In other words, all were considered typically developing children in their school. Third, none of the children had a history of known hearing, visual, neurological, emotional or behavioral problems.

The participants in the study represented four ethnic groups: 16 African-American, 7 Hispanic, 1 Caucasian, and 2 other.

\section{Procedures}

All participants were tested to evaluate reading comprehension, word decoding, receptive vocabulary, receptive and expressive language, narrative skills, cognitive ability and working memory. The tests that were used are as follows:

\section{Reading Tests}

Reading comprehension. Reading comprehension was measured using the Passage Comprehension subtest of the Woodcock Reading Mastery Test, Revised (WRMT-R; Woodcock, 1987). The Passage Comprehension subtest of the WMRT-R uses a cloze procedure and measures reading comprehension ability. Participants were asked to read a sentence or short passages and supply one word that had been deleted.

Decoding skills. Decoding skills were tested using word recognition and nonsense word recognition. The word recognition and word attack tasks were taken from the Word Identification and Word Attack subtests of the Woodcock Reading Mastery Test-Revised (Woodcock, 1987). In the Word Identification subtest, the child was asked 
to read a word orally. The Word Attack subtest requires a child to read non-words. This subtest assesses phonetic decoding abilities. In order to examine the relationship between decoding and reading comprehension, the standard scores from each of the two decoding tasks were used. In addition, for the multiple regression analysis, the decoding score served as an independent variable. This score was a composite score of the Word Identification and Word Attack subtests.

\section{Language Tests}

Receptive vocabulary skill. Receptive vocabulary skills were measured using the Peabody Picture Vocabulary Test, 4th edition (PPVT-4; Dunn \& Dunn, 2007). This is a standardized language test which is commonly used in a clinical setting. Participants were told a word and asked to identify the meaning of the word from a set of four pictures.

Receptive and expressive language skill. Language skills were measured using Core Subtests of the Clinical Evaluation of Language Fundamentals, 4th edition (CELF-4; Semel, Wiig, \& Secord, 2003) The CELF-4 is a standardized, norm-referenced test of receptive and expressive language designed to assess vocabulary, semantic relations and morpho-syntax.

The Core Subtests battery varies by age. For children who are 7 to 8 years of age, the battery includes the following subtests: Concepts and Following Directions to assess receptive language, Word Structure, Recalling Sentences, and Formulated Sentences to assess expressive language. For children who are 9-10 years of age, the battery includes: Concepts and Following Directions, and Word Classes to assess receptive language, and Recalling Sentences, Formulated Sentences, and Word Classes to assess expressive language. Scores from the Core Subtests were combined and converted into standard scores with a mean of 100 and standard deviation of 15.

Narrative skill. Narrative skills were measured using a story retell procedure. From first through fourth grade the following books were used: first grade - Where Are You (Mayer, 1969), second grade -Pookins Gets Her Way (Lester, 1987), third grade - A Porcupine Named Fluffy (Lester, 1986), and fourth grade - Doctor DeSoto (Steig, 1982). To administer the story retell task, the children were asked to listen to an audio-taped verbal narration of the stories while looking at a book. The children were then asked to tell the story using their own words. The participants' narrative samples were audio- and video- recorded for transcription and analysis.

The narrative samples were transcribed using the Systematic Analysis of Language Transcripts (SALT: Miller \& Chapman, 2008). The SALT program provides a 
narrative analysis system that includes the Narrative Scoring Scheme and Subordinate Index to assess story grammar and sentence structure.

The Narrative Scoring Scheme (NSS) is an index of a child's ability to coherently organize a story. This scoring procedure consists of the following seven story characteristics: introduction, character development, mental states, referencing, conflict/ resolution, cohesion, and conclusion. To evaluate responses of each category, a 0 to 5point scoring system was employed: Score of 5 is a proficient response, score of 3 is an emerging or inconsistent, and score of 1 is a minimal or immature. Scores of 2 and 4 are used for intermediate performance. Score of 0 is poor performance including various errors. The scores for all seven categories were combined into a total composite score with the highest possible score being 35 .

The Subordination Index (SI) is an index of syntactic complexity. Narrative samples were segmented into a $\mathrm{C}$-unit which is one main clause or with subordinate clauses. The SI score was calculated by a ratio of total number of clauses (main and subordinate clauses) to the number of utterances (c-unit). Main clauses can stand by themselves, but subordinate clauses are dependent and have to be attached with main clauses.

To determine the interrater reliability of the narrative sample analyses, thirty percent of the participants' narrative samples, two in each grade, were randomly selected and scored by a second trained listener. Cohen's Kappa was performed to determine consistency among the raters. The interrater reliability for the raters was found to be .856 $(p<.001)$, which means the two raters showed relatively high level of agreement on the transcripts.

\section{Cognitive Tests}

Nonverbal intelligence. All participants were administered the Test of Nonverbal Intelligence, 3rd edition (TONI-3; Brown, Sherbenou \& Johnsen, 1997). In this test of nonverbal cognitive ability, each participant was asked to solve problems involving analogies or classification.

\section{Working memory tasks}

Nonword Repetition Task (NRT). The NRT used in this study was developed by Dollaghan and Campbell (1998) and consists of a set of 16 nonsense words that vary from one to four syllables in length with four items at each syllable length. All syllables begin and end with a consonant, creating the following syllable shapes: $\mathrm{CVC}$ (onesyllable), CVCVC (two-syllable), CVCVCVC (three-syllable), and CVCVCVC (foursyllable). There are a total of 96 phonemes assessed in the task. In the NRT, none of 
syllables are meaningful in English in order to reduce the effect of prior vocabulary knowledge. Consonants clusters and late developing consonants are also not used to reduce articulatory difficulty. Only tense vowels are used and the consonants and vowels in each word are used only one time.

The NRT stimuli were audio-recorded by an adult female speaker using a digital voice recorder. The task was administered to participants individually. Participants listened to the stimuli in a quiet room. Before presenting the stimuli, participants were given the following direction, "Now you will hear some made-up words. Say them after me exactly the way that I say them. "Each stimulus was presented only one time. Participants' responses were audio-recorded for transcription and scoring.

Scoring followed the system by Dollaghan and Campbell (1998). The percent of correct phoneme productions for each syllable and across the total set of nonsense syllables were scored. Phoneme substitutions and omissions were scored as incorrect, but phoneme distortions and additions were scored as correct.

To determine the reliability, twenty percent of the participants' responses were randomly selected and transcribed and scored by a second trained listener. Reliability was rated at the phoneme level. Phoneme by phoneme percentage of agreement for judgments of correctness on the NRT was 97.9 percent.

Competing Language Processing Task (CLPT). The CLPT used in this study was developed by Gaulin and Campbell (1994) and consists of 42 simple sentences made up of three words. The participants were asked to judge the veracity of 42 sentences and to recall the last word of each sentence. The task contains two groups at each of six difficulty levels. Difficulty levels are defined by the number of statements to be judged and the number of words to be recalled. For example, at Level 1, one sentence is presented to be judged and one word recalled. At level 6, six sentences are presented to be judged and the last six words recalled.

The CLPT stimuli were audio-recorded by an adult female speaker using a digital voice recorder. The task was presented to participants individually. Participants listened to stimuli in a quiet room, with the following instructions, "I am going to read you some true and false sentences. After each one I want you to say "yes" or "no." After we have done a group of sentences I will ask you to tell me the last word of each sentence in that group. Don't worry about getting them in the right order. As we go on, the groups will have more sentences. It will get hard and you won't be able to ask any questions, but I want you to keep on trying to do the best you can. Remember to say "yes" or "no" after each sentence. Then when I ask you, please say the last word of each sentence you just heard. Do you understand? Let's try some for practice." Each stimulus was presented only one time. Before they began the test items, they were given examples to ensure that all participants understood the task. 
Participants' responses were recorded onto the scoring sheet and included the percentage of sentences responded to correctly, whether the sentence was true or false, and the percentage of words recalled correctly. All responses were audio-recorded for transcription and scoring.

To determine reliability, twenty percent of the participants' responses were randomly selected and transcribed and scored by a second trained listener. The percentage of agreement for words recalled on the CLPT was 100 percent.

\section{General Procedures}

The test order was randomly assigned to each participant. In order to examine the relationship between reading comprehension, standard scores were used if the tests provided a standard score with a mean of 100 and a standard deviation of 15. Standard scores were available for Passage Comprehension, Word Identification, Word Attack, PPVT-4, CELF-4, and TONI-3 administrations. The Narrative retelling tasks that produced NSS and SI scores, the NRT and the CLPT are not standardized so raw scores were used. For the analysis of correlations and multiple regressions, the raw score for Passage Comprehension was used when the other variables were raw scores. In addition, when the raw scores were used in statistical analysis, age was controlled.

Four of the children were unable to complete all of the tests, so there are 8 missing values from a total of 234 values: two missing values on the CELF, two missing values on the PPVT-4, and two missing values on the NRT and the CLPT. 


\section{CHAPTER 3. RESULTS}

\section{Cognitive Skills}

The mean score, standard deviation and range for the nonverbal intelligence test are presented in Table 1 . The average scores for the children in the study fell within one standard deviation of the mean for their age on nonverbal intelligence as measured using the Test of Nonverbal Intelligence Test (TONI-3), with an average standard score of 91.17 (range 75-133). However their average standard score was below the mean of 100 . The boxplot in Figure 1 illustrates the range of scores of the TONI-3, demonstrating that the middle 50 percent of children in the study received a standard score of between 83.75 and 95, with the median score of 89.50. In the boxplot, the $\mathrm{x}$ axis represents the participants, and the $y$ axis represents the standard scores for the TONI-3. It also shows the two outliers representing two children who obtained standard scores of 124 and 133 .

To compare the participants with the standardization sample, independent onesample t-tests were used. For the standardization sample, the test mean is equal to 100 and the standard deviation is 15 . The independent one sample $t$-tests showed that children in this study scored significantly lower on TONI-3, in comparison to the standardization sample, with $t=-3.349, p=.002$. Cohen's $d$ was calculated to measure the size of the difference between the current sample and the standardized sample of the normed tests. The moderate difference between children in this study and the standardization sample from the TONI-3, with $d=-.612$.

\section{Language Skills}

The mean score, standard deviation and range for the PPVT-4, CELF-4, the Narrative Scoring Scheme (NSS) and the Subordination Index (SI) are presented in Table 2. On the Peabody Picture Vocabulary Test (PPVT-4), the participants mean score of 90.57 (range 64-123) was below average but within one standard deviation of the mean of the standardization sample. As can be seen in Figure 2, the middle 50 percent of children in the study received standard scores of between 80.25 and 99.75 on the PPVT- 4 . On the Clinical Evaluation of Language Fundamentals-4 (CELF-4), the children achieved an average score of 83.54 (range 42-126) which is more than one standard deviation below the mean. As can be seen in Figure 2, the middle 50 percent of children in the study obtained standard scores between 66 and 101.50 on the CELF-4.

An independent one samples $t$-test indicated children who live in poverty scored significantly lower on the PPVT-4 and CELF-4 when compared to the standardization sample, with $t=-3.083, p=.005$ and $t=-3.572$ and $p=.002$, respectively. Cohen's $d$ was calculated to measure the size of the differences in PPVT-4 and CELF-4. Large effect sizes were found on the CELF-4, with Cohen's $d=-.858$ while the PPVT-4 had a medium effect size $(d=-.622)$. 
Table 1. Nonverbal intelligence scores

\begin{tabular}{lcccccc}
\hline Assessment & Mean & SD & Range & $\boldsymbol{t}$ & $\boldsymbol{p}$ & $\boldsymbol{d}$ \\
\hline TONI-3 & 91.15 & 13.00 & $75-133$ & -3.469 & .002 & -.630 \\
\hline
\end{tabular}

Note. TONI-3: Test of Nonverbal Intelligence -3 .

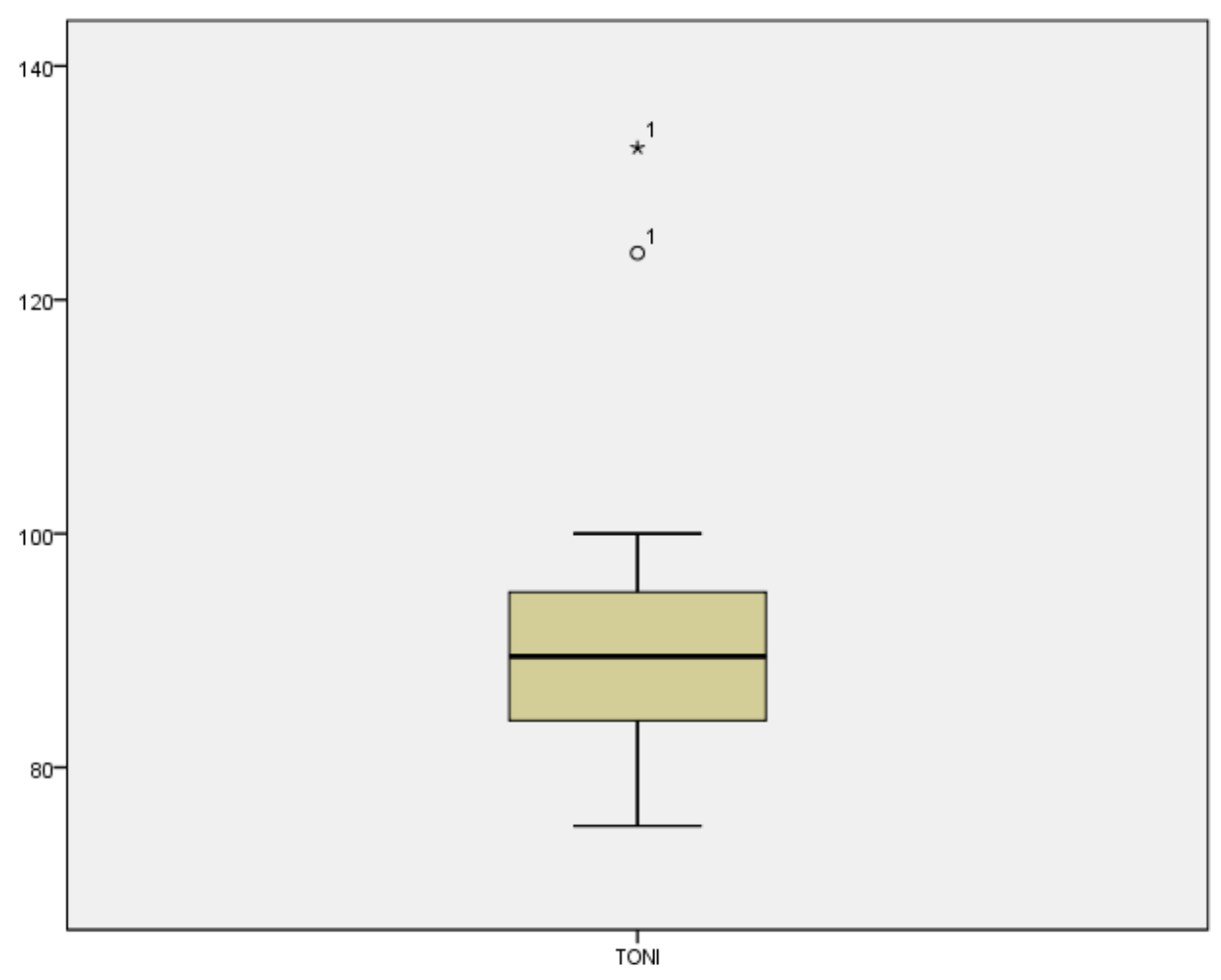

Figure 1. Performance on the TONI-3 
Table 2. Language scores

\begin{tabular}{lcccccc}
\hline Assessment & Mean & SD & Range & $\boldsymbol{t}$ & $\boldsymbol{p}$ & $\boldsymbol{d}$ \\
\hline PPVT-4 $^{\mathrm{a}}$ & 90.75 & 14.70 & $64-123$ & -3.08 & .005 & -.858 \\
CELF-4 $^{\mathrm{a}}$ & 83.54 & 22.28 & $42-126$ & -3.572 & .002 & -.622 \\
NSS $^{\mathrm{b}}$ & 17.27 & 4.90 & $7-25$ & -6.730 & $<0.001$ & -1.330 \\
SI $^{\mathrm{b}}$ & 1.24 & .19 & $96-1.59$ & -1.980 & .048 & -.372 \\
\hline
\end{tabular}

Notes. PPVT-4: Peabody Picture Vocabulary Test-4; CELF-4: Clinical Evaluation of Language Fundamentals-4; NSS: Narrative Scoring Scheme; SI: Subordinate Index. ${ }^{\mathrm{a}}$ Standard score; ${ }^{\mathrm{b}}$ Raw scores.

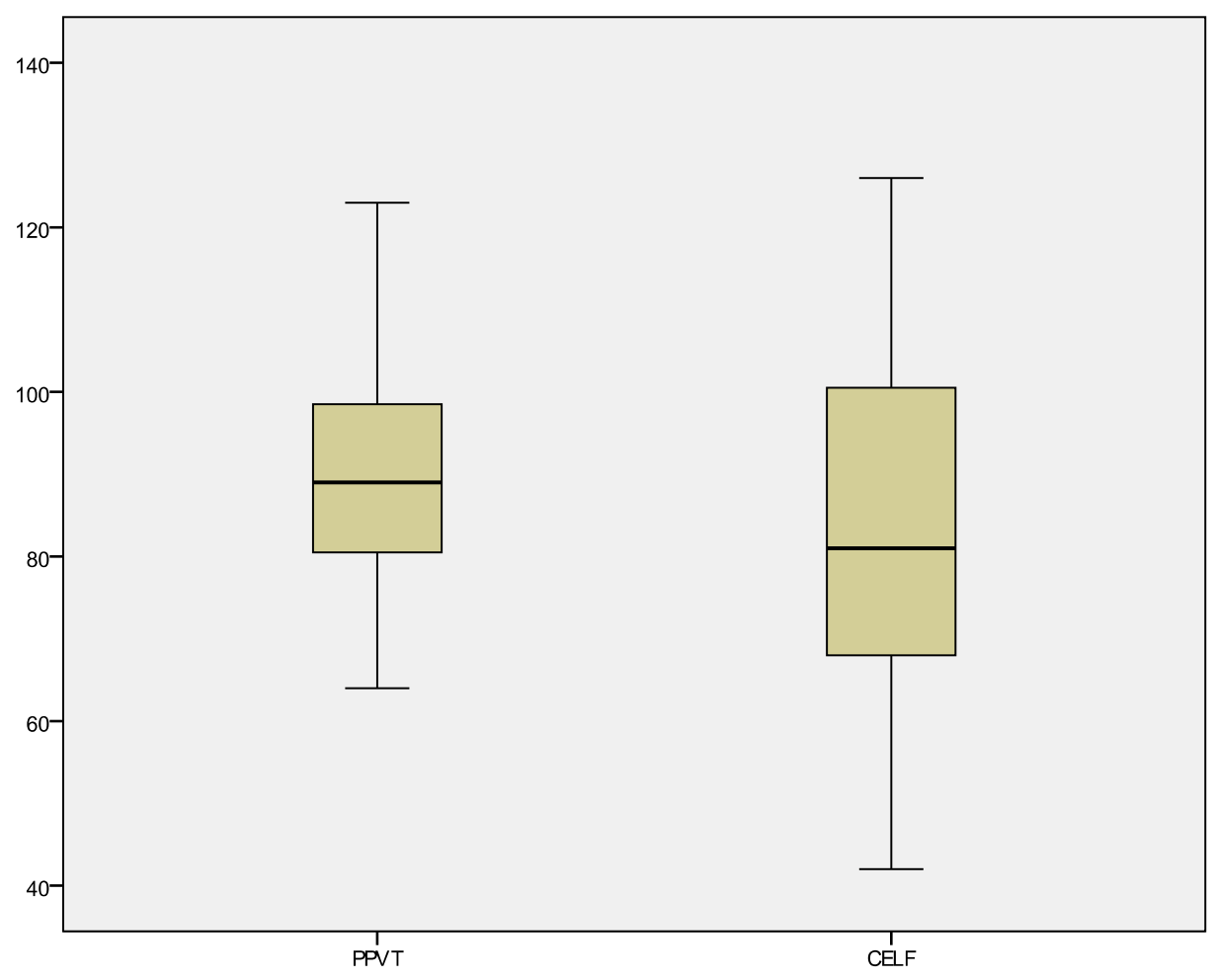

Figure 2. Performance on the PPVT-4 and CELF-4 
The Narrative Scoring Scheme (NSS) and the Subordination Index (SI) are measures of story retelling skills and are not standardized. The Systematic Analysis of Language Transcripts (SALT: Miller \& Chapman, 2008) program provides a dataset for comparing the results for children between 4 to 10 years of age. To compare the results from this study, narrative samples from children ranging from $7 ; 4$ to $10 ; 0$ years of age in the SALT database were selected. From the database, the average score of 23.28 with a standard deviation of 4.32 on the NSS and the average score of 1.30 with a standard deviation of 0.14 on the SI were used to compare to the children in this study. Both the NSS and SI scores for the children in this study were significantly lower than those of scores from the dataset samples $(t=-6.730, p<.001$ for NSS and $t=-1.980$ and $p=.048$ for SI). A large effect size were found on the NSS, $(d=-1.330)$, while SI had a small effect size $(d=-.372)$. Figures 3 and 4 display the mean scores from the NSS and SI, showing that there was clear difference between participants in this study and the dataset from the SALT on the NSS and a slight difference between those two groups on SI.

To investigate the variability of language scores for the participants in this study, performance on the following four language tests was analyzed: 1) the PPVT-4, 2) the CELF-4, 3) the NSS, and 4) SI. On the PPVT-4, 67 percent of the children fell at or above one standard deviation from the mean while 33 percent of children obtained scores one standard deviation below the mean. On the CELF-4, 46 percent of the children obtained a score at or above one standard deviation from the mean while 54 percent of the children fell one standard deviation below the mean. Of this group, 25 percent of the children scored two or more than two standard deviations below the mean of the CELF-4. Forty-six percent of the children fell within the normal range on the NSS, and 58 percent scored at or above 1 standard deviation below the mean on the SI. However, approximately half of the children in the study fell one standard deviation below the mean on the NSS (54 percent) and the SI (42 percent).

Table 3 shows the percentage of children by standard deviation from the mean. On the PPVT-4 and CELF-4, four percent of children obtained scores one standard deviation above the mean. Sixty-three percent of children fell within one standard deviation of the mean on the PPVT-4 and forty-two percent of children obtained scores within one standard deviation of the mean on the CELF-4. In contrast, on the PPVT-4, thirty-three percent of children fell one standard deviation below the man as did and fiftyfour percent of children on the CELF-4. On the narrative tasks, forty-six percent of children scored at or above one standard deviation of the mean on the NSS as did fiftyeight percent of children on the SI. Among the twenty-six children, four scored one standard deviation below the mean on all of the language tests (PPVT-4, CELF-4, NSS and SI) and two children scored 2 standard deviations below the mean on all of the language tests (PPVT-4, CELF-4, NSS and SI). Eight children fell one standard deviation below the mean on both of the standardized tests, the PPVT-4 and CELF-4. Figure 5 is a cumulative bar chart, showing that children in this study demonstrated more difficulty on the CELF-4 and NSS than the PPVT-4 and SI. 


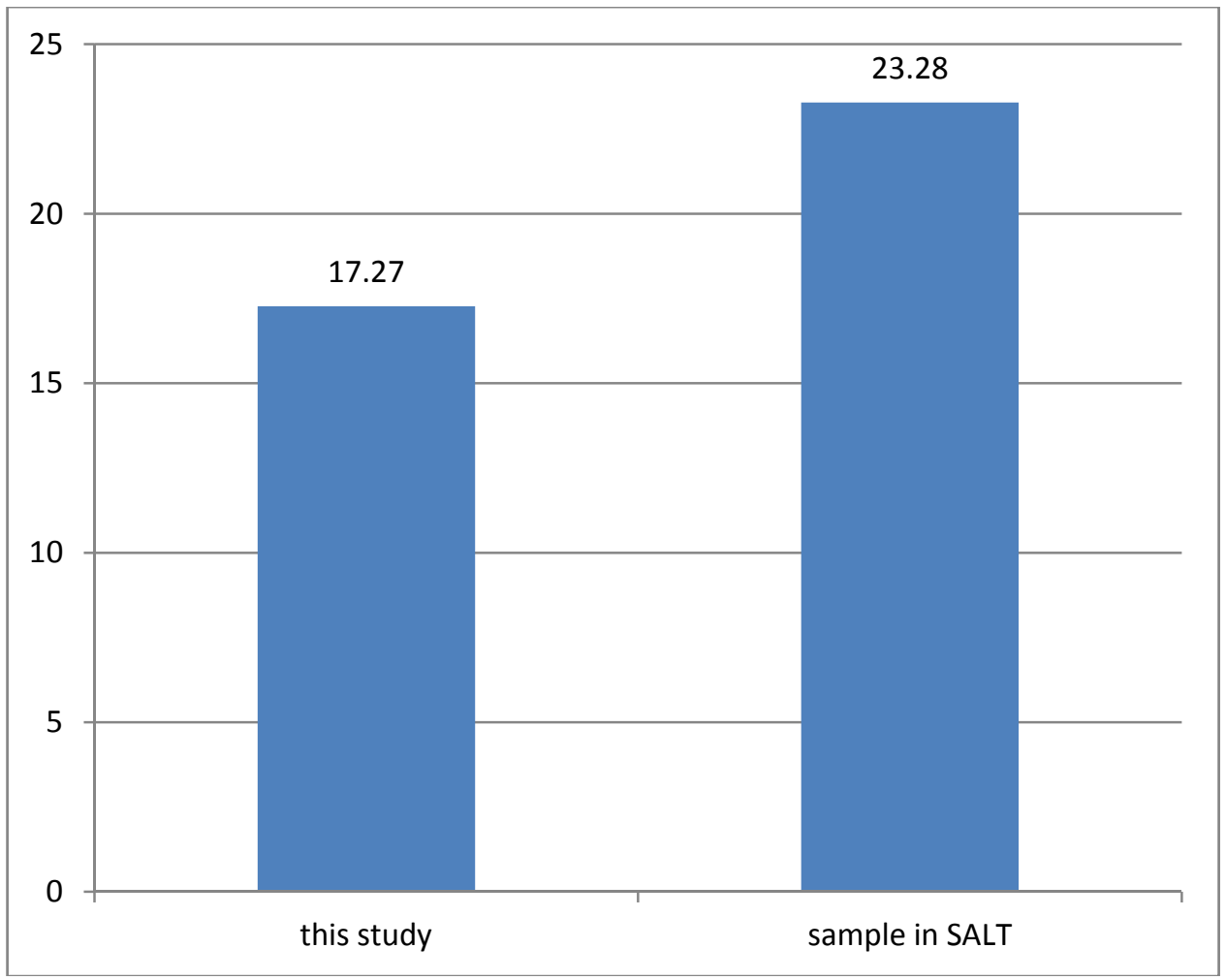

Figure 3. The average score of the NSS for this study and from the SALT database 


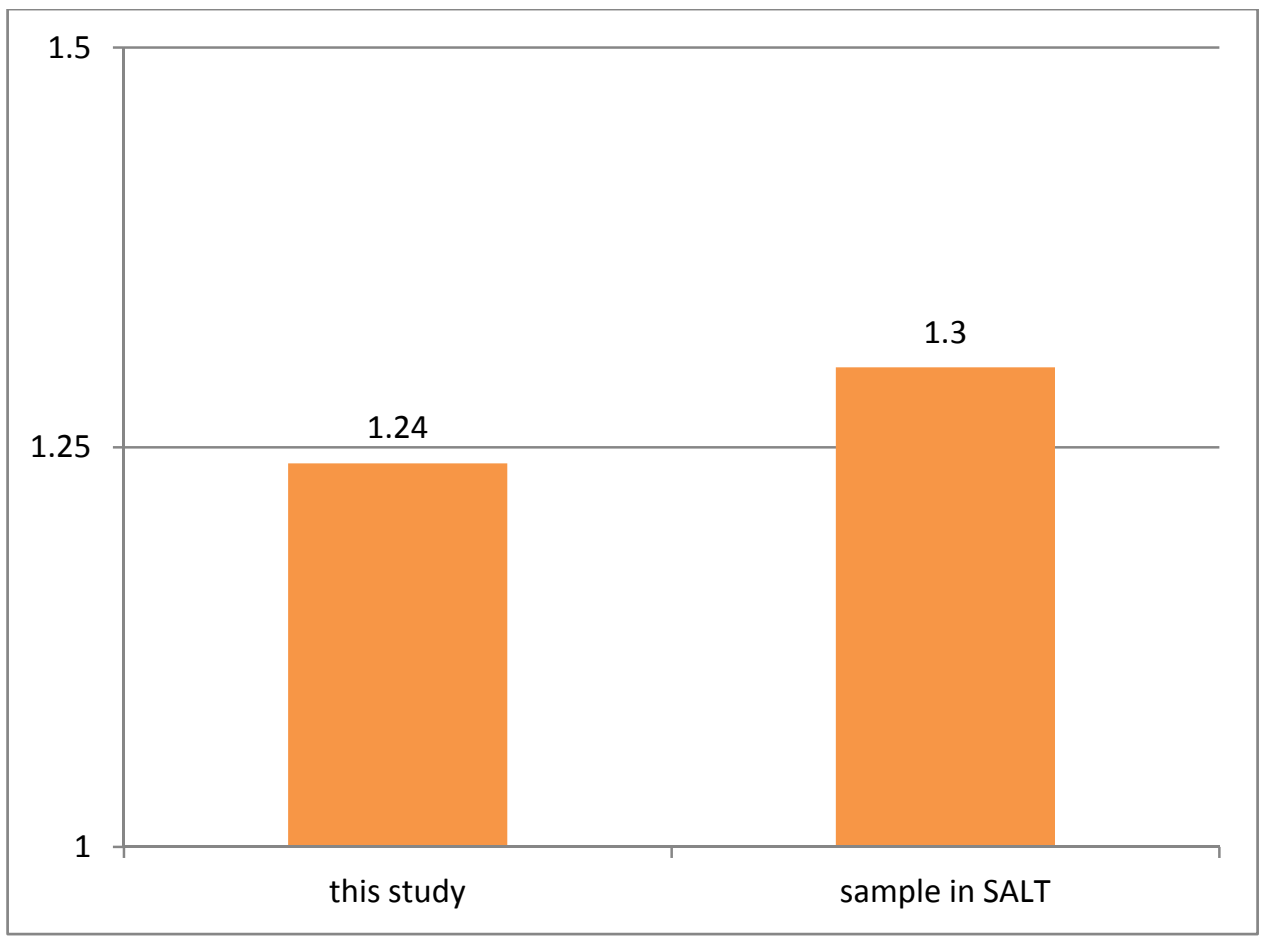

Figure 4. The average score of the SI for this study from the SALT database 
Table 3. Test performance by standard deviation on the language tests

\begin{tabular}{lcccc}
\hline SD & PPVT-4 & CELF-4 & NSS & SI \\
\hline 1SD above the mean & $4 \%$ & $4 \%$ & $0 \%$ & $12 \%$ \\
Within 1SD & $63 \%$ & $42 \%$ & $46 \%$ & $46 \%$ \\
1SD below the mean & $25 \%$ & $29 \%$ & $19 \%$ & $27 \%$ \\
2 SD below the mean & $8 \%$ & $25 \%$ & $35 \%$ & $15 \%$ \\
\hline
\end{tabular}

Notes. PPVT-4: Peabody Picture Vocabulary Test-4; CELF-4: Clinical Evaluation of Language Fundamentals-4; NSS: Narrative Scoring Scheme; SI: Subordinate Index.

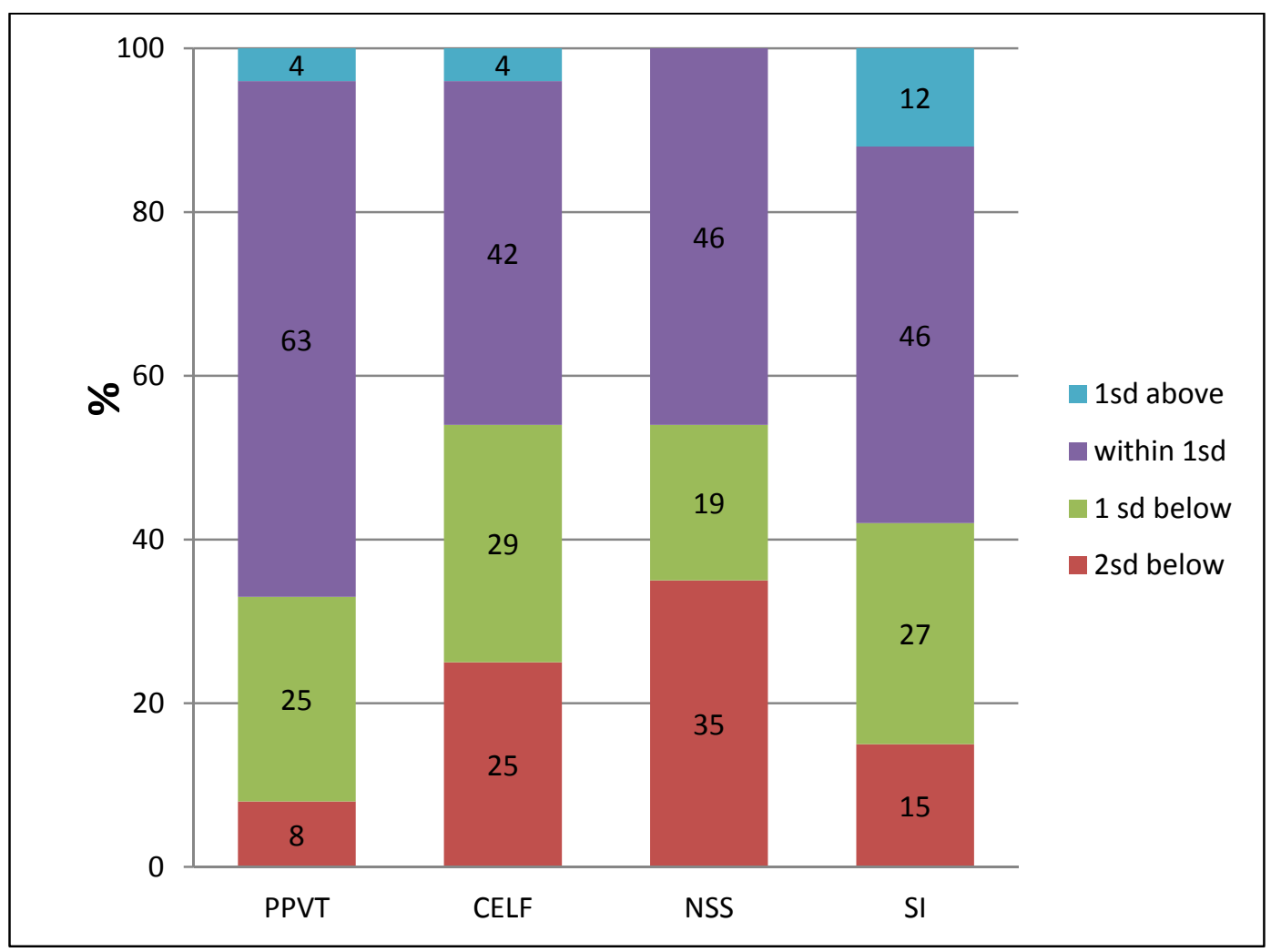

Figure 5. Test performance by standard deviation on the language tests

Notes. PPVT: Peabody Picture Vocabulary Test-4; CELF: Clinical Evaluation of Language Fundamentals-4; NSS: Narrative Scoring Scheme; SI: Subordinate Index. 


\section{Reading Skills}

Table 4 shows the mean score, standard deviation and range of the Word Identification, Word Attack and Passage Comprehension subtests of the Reading Mastery Test-Revised (WRMT-R). Children performed at average levels on the Word Identification and Word Attack subtests WRMT-R. They had an average score of 100.54 (range 73-116) for the Word Identification and 102.31 (range 75-125) for the Word Attack subtests. The children, however, fell below the average on the Passage Comprehension of the WRMT-R, with an average standard score of 93.31 (range 69-109). Figure 6 shows that the middle 50 percent of children obtained standard scores between 92.75 and 112.25 on Word Identification and between 93.75 and 112 on Word Attack . On the Passage Comprehension task, the middle 50 percent of children achieved standard scores between 85.75 and 101.00 .

As can be seen in Table 4, there were no differences in the Word Identification and Word Attack subtest scores from the WRMT-R where the children's mean scores were equal to the mean of the standardization sample. However, the participants in this study obtained significantly lower scores than did the standardization sample on the Passage Comprehension of the WRMT-R $(t=-3.084, p=.005)$, with a medium effect size $(d=-.526)$.

\section{Working Memory Skills}

Scores from the NRT and CLPT working memory tasks are not standardized so they were compared to the mean scores of children from the studies by Archibald and Gathercole (2006), Coady, Evans, and Kluender (2010), Estes, Evans, and Else-Quest (2007) and Montgomery and Evans (2009).

Table 5 displays the performance results from the NRT and CLPT in this study and Table 6 shows the comparison of scores from this study to previous studies. The mean ages of participants in the previous studies ranged from 8.10 to 9.7 compared with the mean age of children in the current study which was 9.1. Children in the current study exhibited a similar performance on the NRT to those groups from previous studies. In contrast, scores on the CLPT in the current study were lower than all groups in previous studies which provided the mean and standard deviations.

Figure 7 and Figure 8 illustrate the comparison of scores from this study and previous research.

In sum, children in this study performed more poorly on tests of nonverbal intelligence, receptive vocabulary, receptive and expressive language, story retelling, and passage comprehension when compared with the standardization samples. However, children in this study did not differ from standardization samples on Word Identification and Word Attack assessments. 
Table 4. Reading scores

\begin{tabular}{lcccccc}
\hline Assessment & Mean & SD & Range & $\boldsymbol{t}$ & $\boldsymbol{p}$ & $\boldsymbol{d}$ \\
\hline WI & 100.54 & 11.23 & $73-116$ & .065 & .948 & .011 \\
WA & 102.31 & 12.72 & $75-125$ & .681 & .502 & .077 \\
PC & 93.31 & 11.23 & $69-109$ & -3.084 & .005 & -.526 \\
\hline
\end{tabular}

Notes. WI: Word Identification of the WMRT-R; WA: Word Identification of the WMRT-R; PC: Passage Comprehension of the WMRT-R.

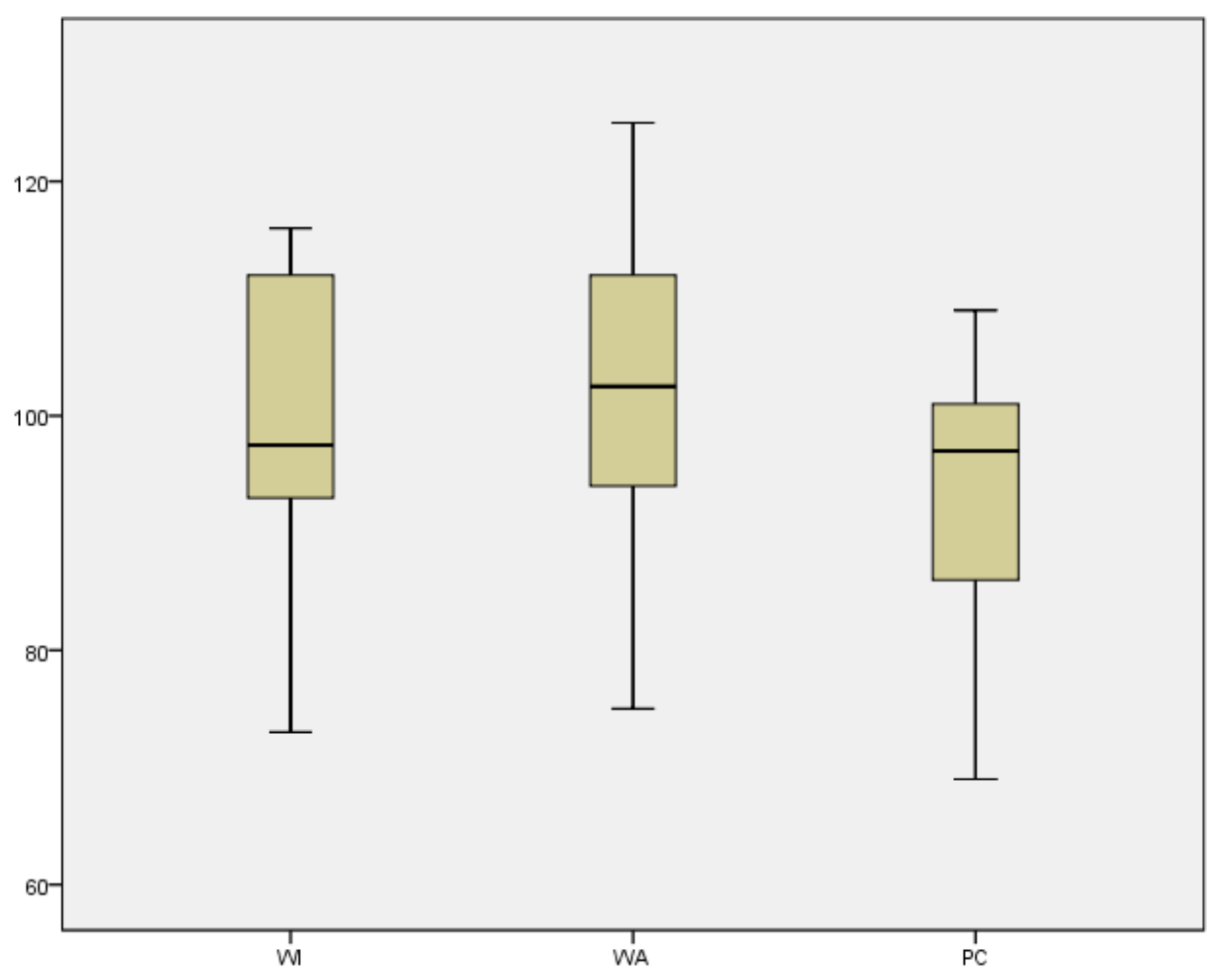

Figure 6. Performance on the Word Identification, Word Attack and Passage Comprehension subtests of the WRMT-R 
Table 5. NRT and CLPT scores using percentage of correct responses

\begin{tabular}{lccc}
\hline Assessment & Mean & SD & Range \\
\hline NRT total & 85.37 & 5.28 & $75-94.79$ \\
NRT 1 syll. & 80.90 & 7.95 & $66.67-91.67$ \\
NRT 2 syll. & 88.75 & 7.26 & $66.67-91.67$ \\
NRT 3 syll. & 85.56 & 7.17 & $75-100$ \\
NRT 4 syll. & 84.60 & 7.72 & $61.11-94.44$ \\
CLPT comp & 96.52 & 3.13 & $88.10-100$ \\
CLPT recall & 44.84 & 16.05 & $2.38-61.90$ \\
\hline
\end{tabular}

Notes. NRT: Nonword Repetition Task; CLPT comp: Sentence Comprehension task of the Competing Language Processing Task; CLPT recall: Word-recall task of the CLPT. 
Table 6. NRT and CLPT scores from this study and previous studies

\begin{tabular}{lccccc}
\hline Assessment & This study (2011) & $\begin{array}{c}\text { Coady et al. } \\
(\mathbf{2 0 1 0})\end{array}$ & $\begin{array}{c}\text { Montgomery \& } \\
\text { Evans (2009) }\end{array}$ & $\begin{array}{c}\text { Estes et al. } \\
(\mathbf{2 0 0 7})\end{array}$ & $\begin{array}{c}\text { Archibald \& } \\
\text { Gathercole (2006) }\end{array}$ \\
\hline$N$ & 26 & 18 & 18 & N/A & 12 \\
Age & $9 ; 0(7 ; 4-10 ; 8)$ & $8 ; 10(7 ; 4-10 ; 0)$ & $9 ; 1(7: 5-12 ; 10)$ & $9 ; 6$ & $9 ; 7(7 ; 0-12 ; 5)$ \\
Language & $90.75(\mathrm{PPVT})$ & $\mathrm{N} / \mathrm{A}$ & $108.7(\mathrm{PPVT}-3)$ & $\mathrm{N} / \mathrm{A}$ & $107.17(\mathrm{BPVS}-\mathrm{II})$ \\
(SS) & $83.54(\mathrm{CELF})$ & $103.7(\mathrm{CELF}-\mathrm{E})$ & & & $108.58(\mathrm{TROG})$ \\
NRT & $85.5(5.3)$ & $82.9(8.4)$ & $90.3(4.9)$ & $86.0(7.5)$ & $88.26(4.77)$ \\
CLPT recall & $44.4(16.2)$ & $48.3(12.7)$ & $62.1(14.3)$ & $\mathrm{N} / \mathrm{A}$ & $\mathrm{N} / \mathrm{A}$ \\
\hline
\end{tabular}

Notes. N/A: Data not available; CELF-E: CELF-Expressive language score; CLPT recall: Word-recall task of the CLPT; SS: Standard Score. 


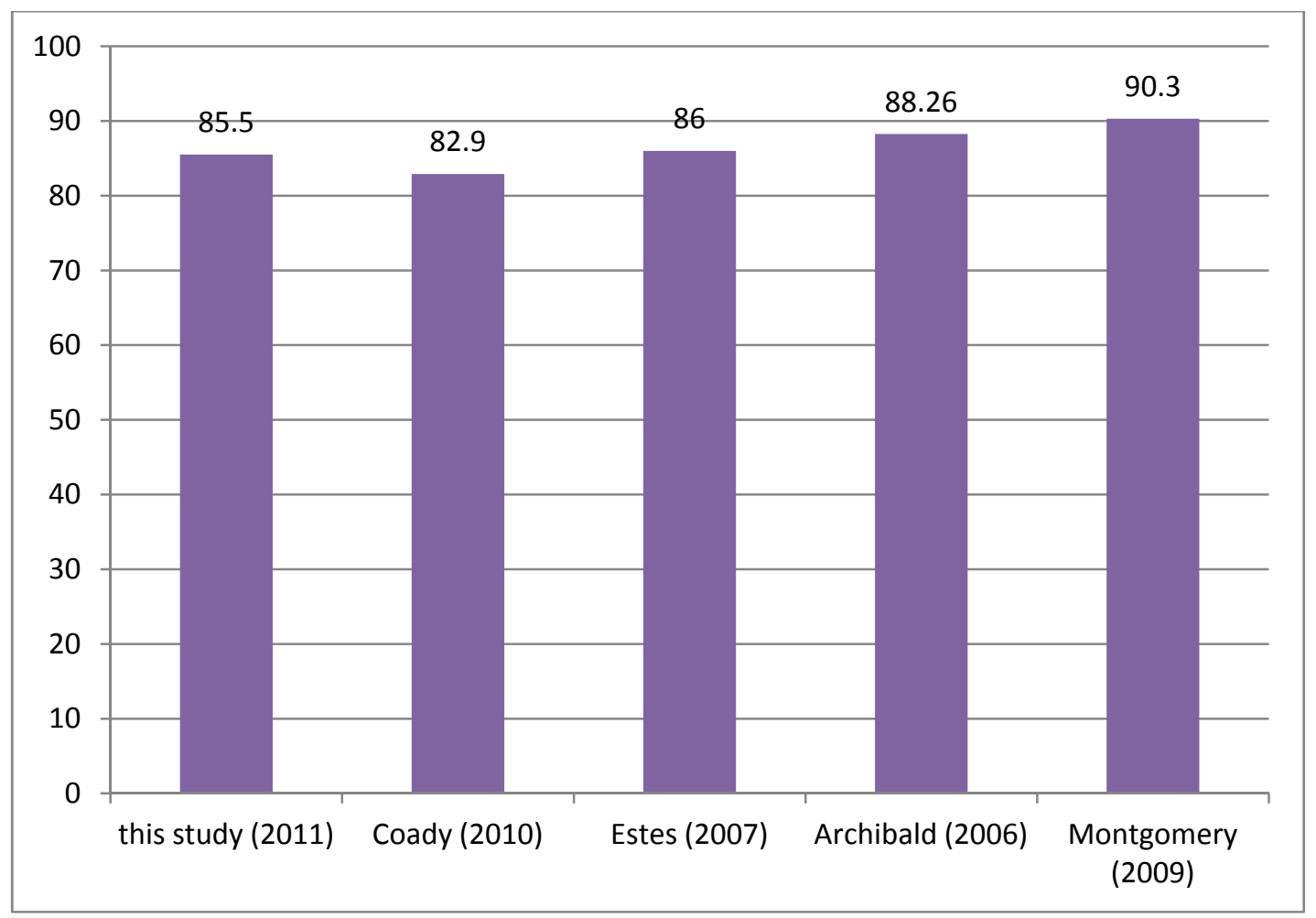

Figure 7. Average percentages for the total number of phonemes recalled correctly on the NRT from this study and previous studies 


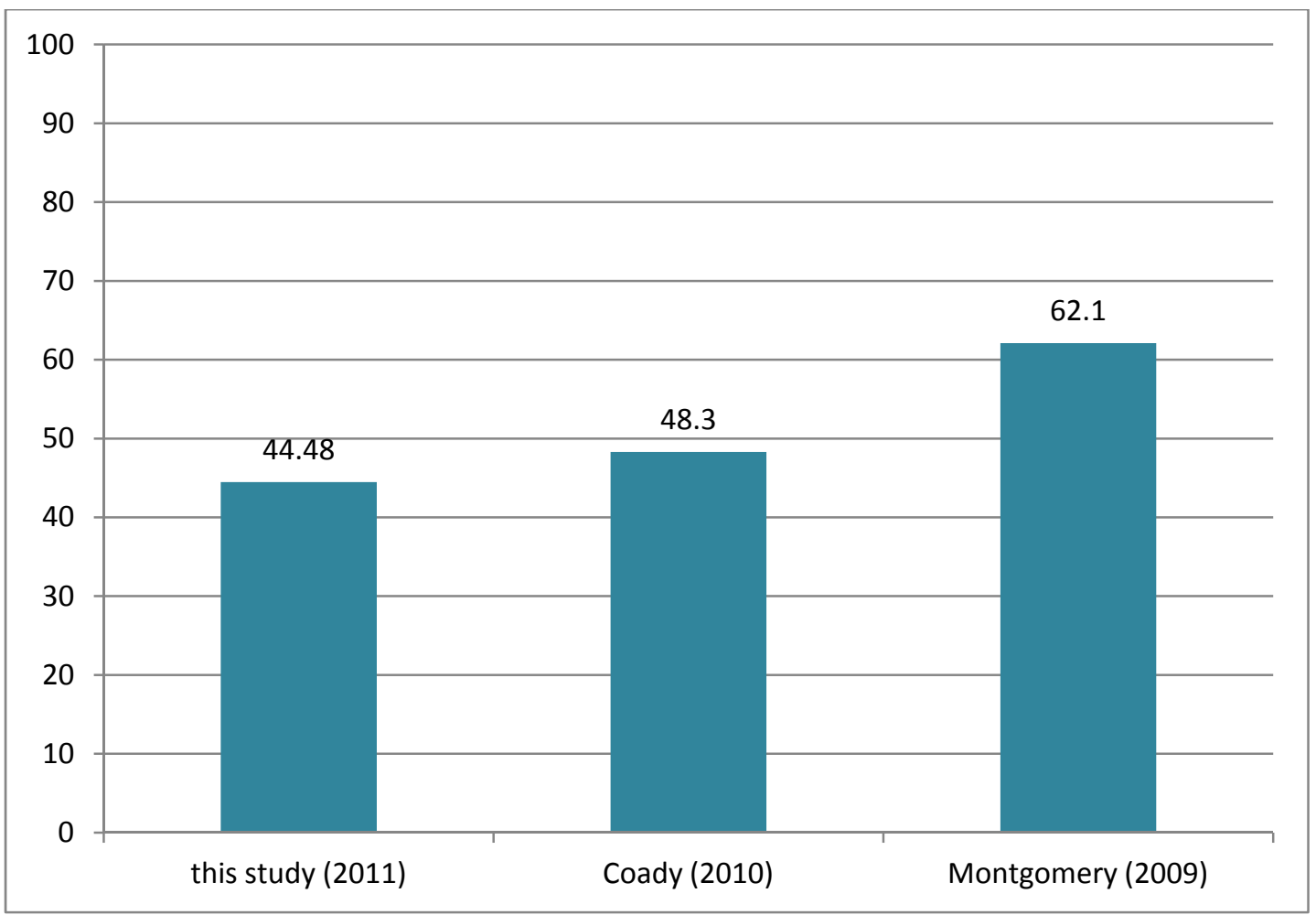

Figure 8. Average percentages for the total number of words recalled correctly on the CLPT from this study and previous studies 


\section{The Relationship between Passage Comprehension and Cognitive, Working Memory, Language, and Decoding Scores}

To examine the relationship between passage comprehension and other variables, Pearson Product-moment correlations were used. Tables 7 and 8 show the correlations between passage comprehension and nonverbal intelligence, working memory, language and decoding scores. The NRT, CLPT, NSS, and SI tasks were not standardized, so that their raw scores were used. Therefore, correlation analysis was conducted by controlling for age to examine the correlation between passage comprehension and those tasks.

As shown in the Table 7, all variables were moderately to highly correlated with Passage Comprehension ranging from .433 to .873 . The CELF-4 was highly correlated with passage comprehension $(r=.795, p<.001)$ and the PPVT-4 was also correlated with passage comprehension $(r=.697, p<.001)$. For the decoding tests, high correlations were found between Passage Comprehension and Word Identification and Word Attack, $r$ $=.873, p<.001$, and $r=.828, p<.001$, respectively. The TONI-3 did show a correlation with Passage Comprehension $(r=.494, p=.022)$.

Figure 9, 10 and 11 illustrates the relationship between Passage Comprehension and the CELF-4, Word Identification, and Word Attack. In this figure, the slopes of the linear relationships were positive, meaning that better performance on the language and decoding tests were related to better performance on the reading comprehension test.

Among the variables are some non-standardized tests that do not provide standard scores, so raw scores were used to examine correlations. Age was correlated to syntactic complexity and approached significance with the sentence comprehension and recall tasks of the CLPT $(r=.395, p=.056$, and $r=.392, p=.058)$. Thus, age was controlled for all partial correlations. The partial intercorrelations between Passage Comprehension, total number of phonemes recalled correctly on the NRT, the sentence comprehension task of the CLPT, the word-recall task of the CLPT, NSS, and SI are displayed in Table 8. After controlling for age effects, the Passage Comprehension score was highly correlated with the word recall task of the CLPT, $r=.846, p<.001$. There were correlations between passage comprehension and the NRT and the sentence comprehension task of the CLPT ( $r=.551, p=.006$ and $r=.647, p=.001$, respectively). The NSS was also moderately correlated with Passage Comprehension, $r=.564, p=.010$. However, the SI did not show a significant correlation with the Passage Comprehension scores.

Hierarchical multiple regressions were conducted to determine which variables of decoding and language would contribute to passage comprehension for children in this study. The composite score of Word Identification and Word Attack as the decoding variable and the core score of the CELF-4 as a language variable were used for the regression. In the first model, decoding was entered the first time, and then was followed by language. As displayed in the Table 9, performance on decoding accounted for 78 percent of the variance, and the core score of the CELF accounted for 3.9 percent of additional variance in Passage Comprehension. In the second model, language was entered the first time, and then was followed by decoding. In this model, language 
Table 7. Correlations between Passage Comprehension and nonverbal intelligence, language and decoding scores

\begin{tabular}{lcccccc}
\hline Assessment & $\mathbf{1}$ & $\mathbf{2}$ & $\mathbf{3}$ & $\mathbf{4}$ & $\mathbf{5}$ & $\mathbf{6}$ \\
\hline 1 TONI-3 & 1 & .382 & $.475^{*}$ & $.524^{* *}$ & $.425^{*}$ & $.494^{*}$ \\
2 PPVT-4 & & 1 & $.784^{* * *}$ & $.764^{* * *}$ & $.500^{*}$ & $.683^{* *}$ \\
3 CELF-4 & & & 1 & $.794^{* * *}$ & $.572^{* *}$ & $.792^{* * *}$ \\
4 WI & & & & 1 & $.860^{* * *}$ & $.873^{* * *}$ \\
5 WA & & & & & 1 & $.828^{* * *}$ \\
6 PC & & & & & & 1 \\
\hline
\end{tabular}

Notes. TONI: Test of Nonverbal Intelligence Test-3; PPVT-4: Peabody Picture Vocabulary Test-4; CELF-4: Clinical Evaluation of Language Fundamentals-4; WI: Word Identification of the WMRT-R; WA: Word Identification of the WMRT-R; PC: Passage Comprehension of the WMRT-R.

${ }^{*} p<.05,{ }^{* *} p<.01,{ }^{* * *} p<.001$. 
Table 8. Partial correlations between Passage Comprehension and NRT, CLPT, NSS and SI after controlling for age

\begin{tabular}{|c|c|c|c|c|c|c|}
\hline Assessment & 1 & 2 & 3 & 4 & 5 & 6 \\
\hline $1 \quad$ NRT & 1 & $.628^{* *}$ & $.430^{*}$ & $.435^{*}$ & -.018 & $.551^{*}$ \\
\hline CLPT comp & & 1 & $.634^{* *}$ & $.485^{*}$ & .111 & $.647^{* *}$ \\
\hline CLPT recall & & & 1 & $.557^{* *}$ & .331 & $.846^{* * *}$ \\
\hline NSS & & & & 1 & $.743^{* * *}$ & $.564^{*}$ \\
\hline SI & & & & & 1 & .371 \\
\hline $\mathrm{PC}$ & & & & & & 1 \\
\hline
\end{tabular}

Notes. NRT: Nonword Repetition Task; CLPT comp: sentence comprehension task of the Competing Language Processing Task; CLPT recall: word-recall task of the CLPT; NSS: Narrative Scoring Scheme; SI: Subordinate Index; PC: Passage Comprehension of the WMRT-R.

${ }^{*} \mathrm{p}<.05,{ }^{* *} \mathrm{p}<.01,{ }^{* * *} \mathrm{p}<.001$. 


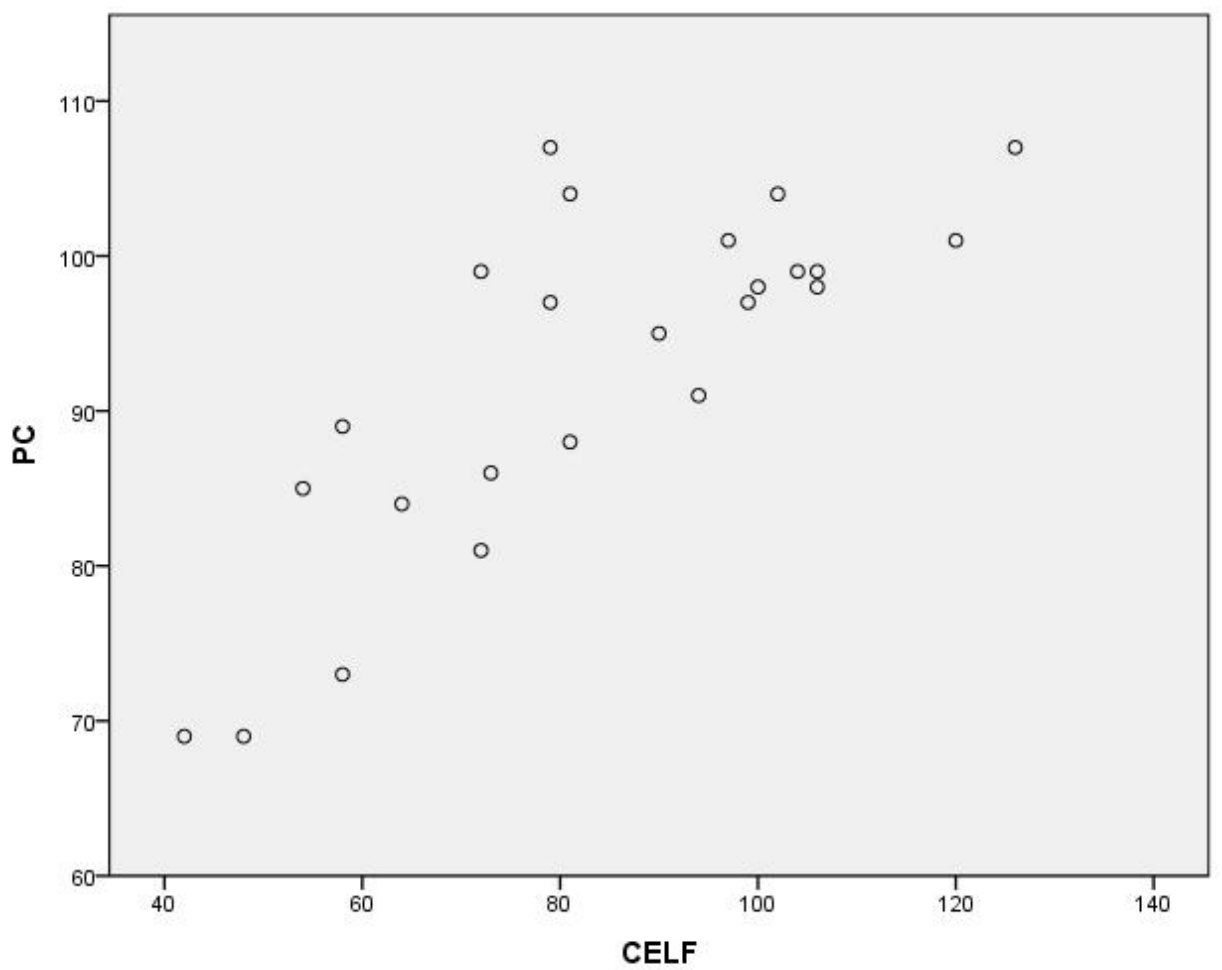

Figure 9. The relationship between Passage Comprehension and CELF-4 scores 


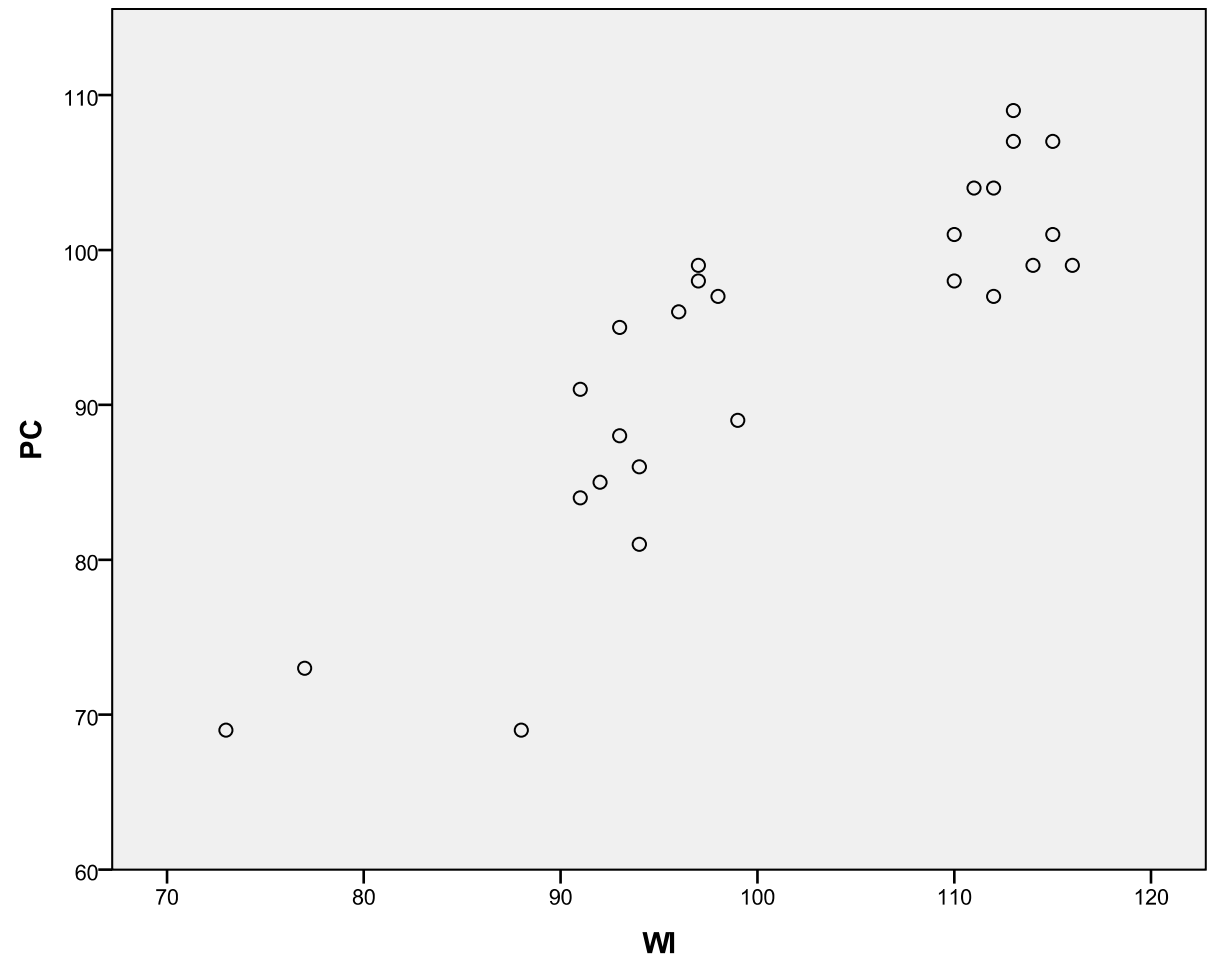

Figure 10. The relationship between Passage Comprehension and Word Identification scores 


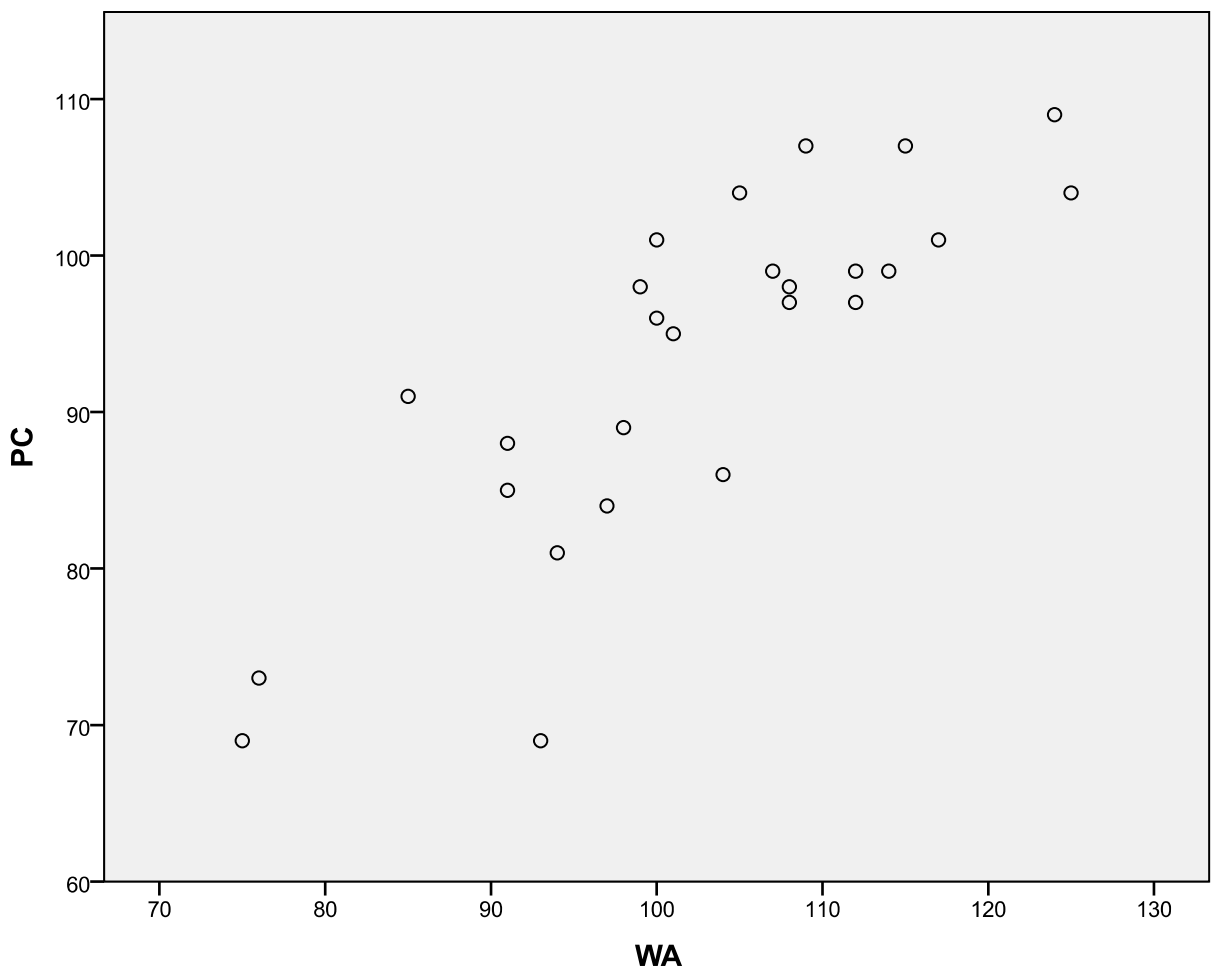

Figure 11. The relationship between Passage Comprehension and Word Attack scores 
Table 9. Hierarchical multiple regression analyses predicting Passage

Comprehension using decoding and language scores

\begin{tabular}{lccccccc}
\hline Step & Variable & $\boldsymbol{b}$ & $\boldsymbol{S E} \boldsymbol{b}$ & $\boldsymbol{B}$ & $\boldsymbol{R}^{2}$ & $\Delta \boldsymbol{R}^{2}$ & $\boldsymbol{F}$ Change \\
\hline Model 1 & & & & & & & \\
& 1 Decoding & .540 & .116 & .657 & .780 & & $78.141^{* * *}$ \\
& 2 Language & .149 & .070 & .301 & .820 & .039 & $47.701^{* * *}$ \\
Model 2 & & & & & & & \\
& 1 Language & .149 & .070 & .301 & .632 & & $37.787^{* * *}$ \\
& 2 Decoding & .540 & .116 & .657 & .820 & .188 & $41.701^{* * *}$ \\
\hline
\end{tabular}

Notes. Decoding: Composite score of Word Identification and Word Attack; Language: Core score of the CELF-4.

${ }^{* * *} p<.001$. 
explained 63.2 percent of variance, and decoding accounted for 18.8 percent of the additional variance in Passage Comprehension. Therefore, when the first and second models from the multiple regression analysis were compared, decoding skill explained passage comprehension slightly more than the language score.

\section{Processing Dependent Measures as Predictors of Reading Comprehension}

Pearson Produce-Moment correlations were used to investigate the relationship between passage comprehension and nonverbal intelligence and working memory tasks. In Table 8, the percentage of words recalled on the CLPT correlated highly with Passage Comprehension after controlling for age $(r=.846, p<.001)$. Nonverbal intelligence, measured using the Test of Nonverbal Intelligence-3, was moderately correlated with Passage Comprehension ( $r=.494, p=.017)$. There were also moderate correlations between Passage Comprehension and the NRT and the sentence comprehension task of the CLPT after controlling for age, with $r=.551, p=.006$ and $r=.647, p=.001$, respectively. As can be seen from Figure 12, 13, 14, and 15, all relationships were positive and linear.

In order to examine the extent to which cognitive measures account for reading comprehension, a bivariate regression analyses which included only one cognitive variable after controlling for age were used. As displayed in the Table 10, the bivariate regression including only the TONI-3 explained 31.9 percent additional variance for reading comprehension beyond age. On the working memory tasks, the NRT explained 20.4 percent of additional variance while the word recall task of the CLPT accounted for 48 percent of the variance after controlling for age. Therefore, the recall task of the CLPT among the processing dependent measures was more predictive of reading comprehension than the TONI-3. 


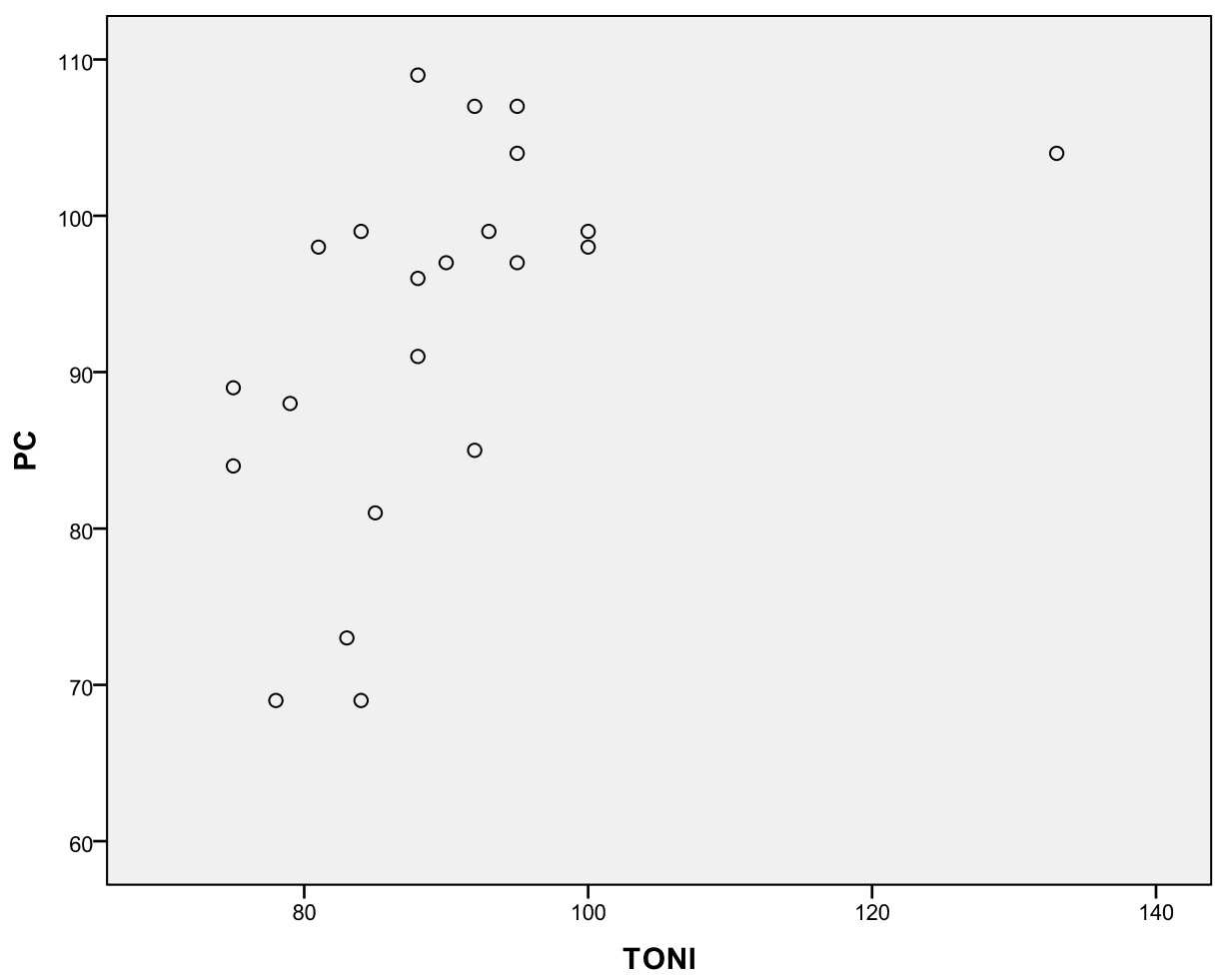

Figure 12. The relationship between Passage Comprehension and TONI-3 scores 


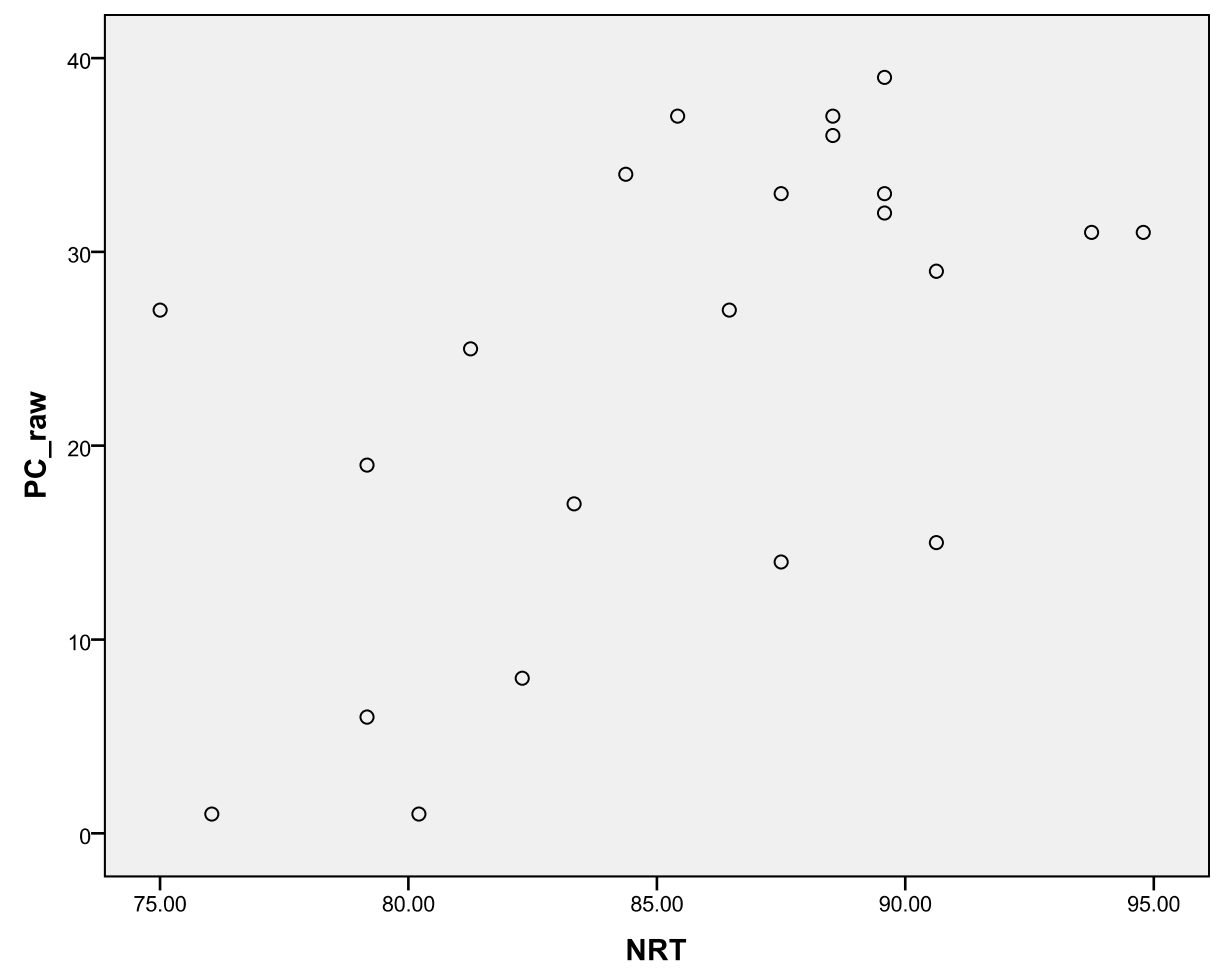

Figure 13. The relationship between Passage Comprehension and NRT scores 


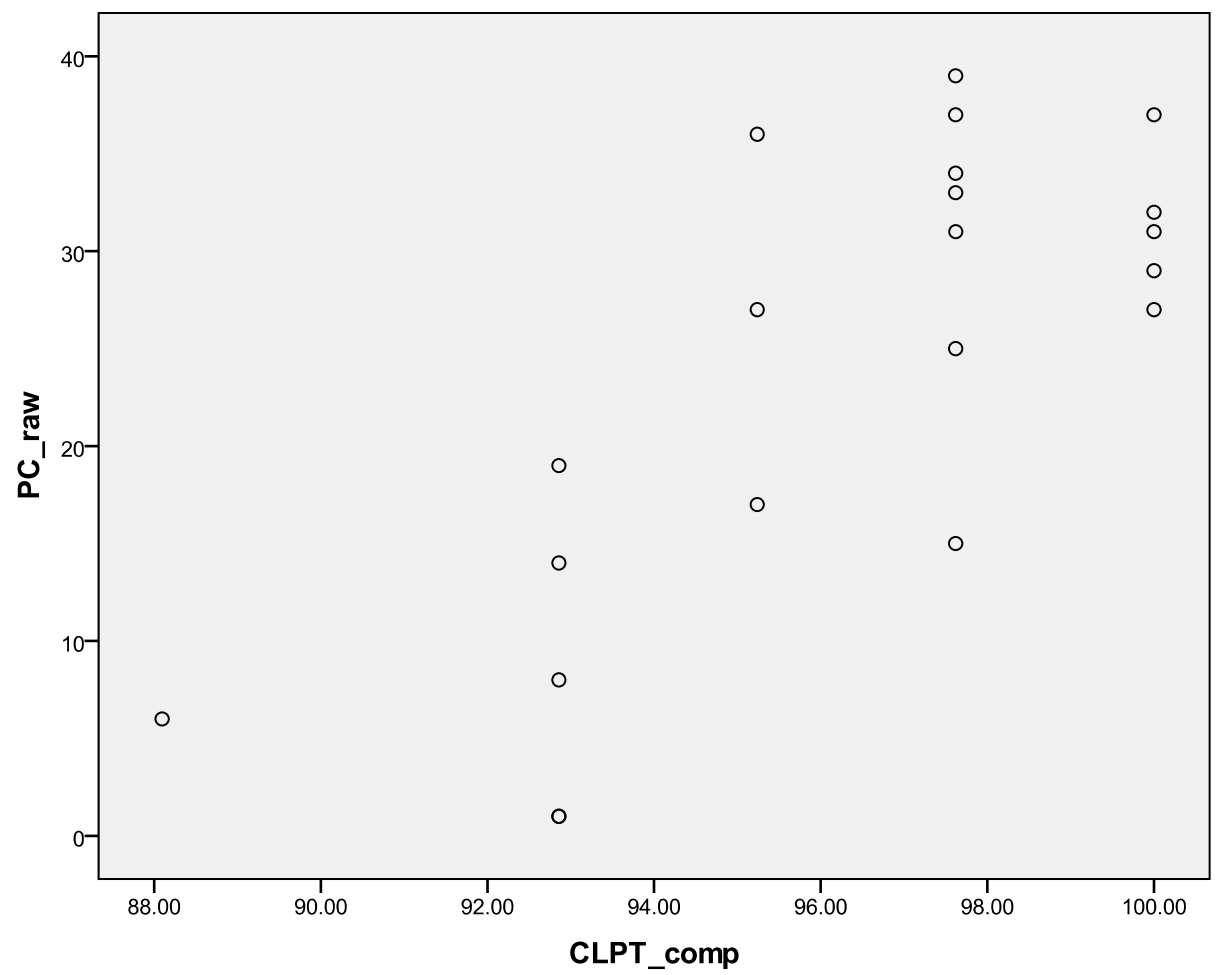

Figure 14. The relationship between Passage Comprehension and the sentence comprehension of the CLPT scores 


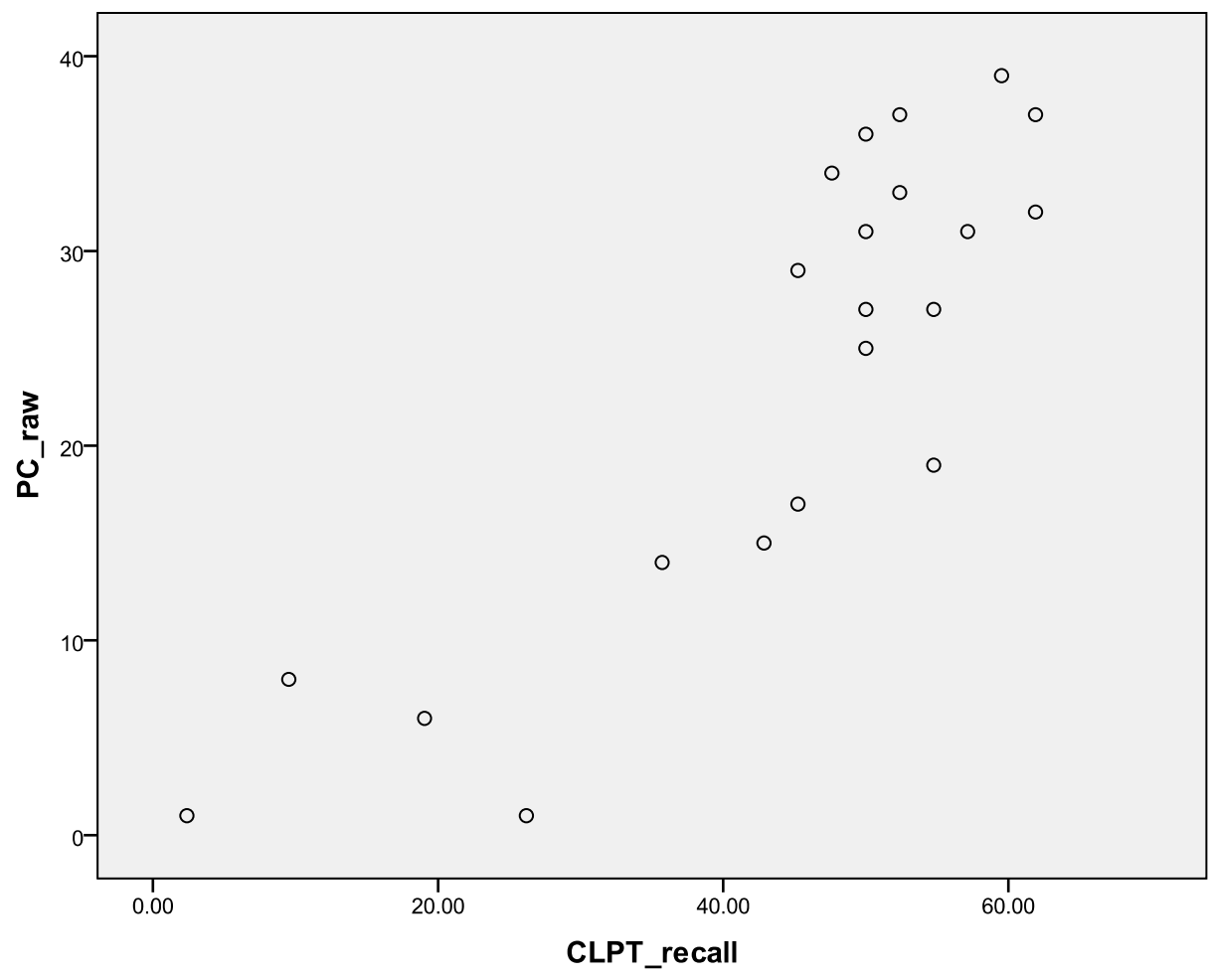

Figure 15. The relationship between Passage Comprehension and the word-recall task of the CLPT scores 
Table 10. Bivariate regression analyses predicting Passage Comprehension using TONI-3, NRT and CLPT scores

\begin{tabular}{lccccccc}
\hline Step & Variable & $\boldsymbol{b}$ & $\boldsymbol{S} \boldsymbol{E} \boldsymbol{b}$ & $\boldsymbol{\beta}$ & $\boldsymbol{R}^{2}$ & $\Delta \boldsymbol{R}^{2}$ & $\boldsymbol{F}$ change \\
\hline Model 1 & & & & & & & \\
& Age & .506 & .133 & .464 & .353 & & $13.098^{* *}$ \\
& TONI-3 & 1.169 & .247 & .580 & .672 & .319 & $18.604^{* * *}$ \\
Model 2 & & & & & & & \\
& Age & .493 & .169 & .450 & .330 & & $10.824^{* *}$ \\
& NRT & 1.101 & .364 & .468 & .533 & .204 & $12.002^{* * *}$ \\
Model 3 & & & & & & & \\
& Age & .305 & .113 & .279 & .330 & & $10.824^{* *}$ \\
& CLPT & 1.332 & .183 & .753 & .810 & .485 & $44.635^{* * *}$ \\
\hline
\end{tabular}

Notes. TONI-3: Test of Nonverbal Intelligence Test-3; NRT; Nonword Repetition Task; CLPT: word-recall task of the CLPT.

${ }^{* *} p<.01,{ }^{* * *} p<.001$. 


\section{CHAPTER 4. DISCUSSION}

The purpose of this study was to investigate the relationship between reading comprehension and the prerequisite skills typically assessed by a school-based speechlanguage pathologist with a focus on children raised in poverty. Based upon previous studies, three hypotheses were developed. First, children from low SES backgrounds would not perform as well as children from the standardization sample on normreferenced language tests although the language tests would predict reading comprehension. Second, decoding would not be as good a predictor of reading comprehension for children from low SES backgrounds as it is in typically developing children from middle SES backgrounds because of differences in language ability. Third, processing dependent measures (working memory) would be more predictive of reading comprehension than nonverbal IQ testing for children from low SES backgrounds.

\section{Language Skills and Reading Comprehension}

First, it was hypothesized that children from low SES homes would not perform as well on standardized language tests as children represented in the standardization samples although the language scores would still predict reading comprehension. Children in this study performed significantly poorer than the standardization sample on all four language measures which included the PPVT-4, CELF-4, and the NSS and SI scores of the narrative task. The results showed that children in this study, on average, scored one standard deviation below the mean on the CELF-4, a measure of receptive and expressive language skills. They also achieved below average scores on receptive vocabulary knowledge, as measured by PPVT-4, even though they fell within the normal range. On the narrative task, children demonstrated significantly poorer performance than age-matched children from the SALT dataset on both narrative structure and syntactic complexity. These results are consistent with previous studies that found poorer performance for children in poverty than those from a national standardization sample (Pruitt, 2006; Storch \& Whitehurst, 2002; Washington \& Craig, 1999; Whitehurst, 1997).

In this study, almost thirty three percent of participants scored more than one standard deviation below the national average on both the PPVT-4 and CELF-4. Fiftyfour percent of the children fell one standard deviation below the mean on the CELF-4, and thirty-one percent of children scored one standard deviation below the mean on the PPVT-4. Fifty-four percent of the children fell one standard deviation below the mean on the NSS which measures knowledge of narrative structure, and forty-two percent of the children fell one standard deviation below the mean on the SI which is an index of syntactic complexity. Results also indicated that seventeen percent of children scored one standard deviation below the mean on all four language measures. Given that all the children in this study were typically developing and that none of them were receiving special education services, these results may be surprising. However, these results are similar to those from previous studies investigating children in poverty. In a study by Pruitt (2006) forty-seven percent of children fell one standard deviation below the mean 
on the PPVT-III. A similar study by Whitehurst (1997) found that eighty-five percent of children scored below average on both the PPVT-R and EOWPVT.

The results from this study show that the children from low SES families obtained significantly lower scores on the SI, a measure of syntactic complexity used during story retelling tasks. Findings regarding syntactic knowledge have not been consistent across previous studies. Whitehurst (1997) found that preschool children in poverty scored within the average range of syntactic skills. Similarly, Pruitt and Oetting (2009) reported that six-year-old African American children from low SES homes were comparable to their peers from middle SES backgrounds on MLU and past tense marking tasks even though they obtained lower scores on the TOLD-P: 3. A study by Storch and Whitehurst (2002), however, found that the average Word Structure score on the CELF-R with first graders from low SES backgrounds fell below the mean.

These results may be explained by the developmental trajectory of syntactic development. There is strong evidence that language input varies in terms of quality, amount and frequency depending on SES. Parents from middle to high SES backgrounds tend to provide longer and more complex syntactic structures to their children (Hart \& Risley, 1995). In the early stages of creating sentences with simple syntactic structures, children across SES backgrounds do not differ. However, as children get older and start to produce more complex syntactic structures, the groups diverge. Specifically, children from middle to high SES backgrounds are more likely to start to produce longer syntactic structures than those from low SES backgrounds (Vasilyeva, Waterfall, \& Huttenlocher, 2008). Researchers also state that sentence length and complexity appear to play key roles in syntactic development at school age (Nippold, Hesketh, Duthie, \& Mansfield, 2005). Therefore, syntactic complexity as measured by the story retelling task may differ according to SES, showing that children from low SES backgrounds produce shorter sentences, less frequent uses of clausal conjunctions, and less complex sentences than those from middle to high SES backgrounds.

In summary, these results are consistent with previous studies that show that poverty or low SES has a negative effect on language skills (Fazio et al., 1996; Washington, 2001; Washington \& Craig, 1999). Children from low SES families are more likely to experience limited language and cognitive stimulation from home environment, support with reading or academic attainment, and fewer material resources such as pencils and books. As the result of an inadequate language learning environment, school-age children from low SES homes tend to have small vocabulary sizes, less complex syntactic knowledge and less sophisticated knowledge of story structure. These play an essential role in both reading comprehension and decoding skills (Clegg \& Ginsborg, 2006; Hart \& Risley, 1995; Roseberry-McKibbin, 2008).

Although the scores on language tests revealed that the children in this study did not score as well as the standardization samples, the language scores were highly correlated with reading comprehension scores. The result from this study is consistent with previous studies that found poor comprehension skills to be related to poor language skills for children (Cain \& Oakhill, 2006; Catts et al., 2006). Specifically, narrative 
structure was highly correlated with reading comprehension. This study confirms previous findings that knowledge about story structure plays an important role in reading comprehension (Cain et al., 2004; Cain \& Oakhill, 1996; Reese, Suggate, Long, \& Schaughency, 2010).

Findings from this study also support the hypothesis that children who are from low SES homes are likely to show lower performance than the standardization sample from standardized, norm-referenced language tests. Although poverty is believed to provide the most likely explanation for these language test results, it is possible that test bias against culturally and linguistically diverse groups also plays a role. Of the participants in this study, eighty eight percent were African-American or Hispanic. Studies have shown that cultural and linguistic minority children are more likely to obtain lower scores on standardized tests than majority children (Dollaghan \& Campbell, 1997). However, a study by Qi, Kaiser, Milan and Hancock (2006) demonstrated that when both income levels and cultural and linguistic diversity are addressed, income levels are more critical. In their study, preschool African-American children from low-income families did not differ from European-American children of similar income levels on the PPVT-III. Thus, poverty or SES background was more predictive of language skills than cultural and linguistic diversity in preschool.

\section{Decoding Skills and Reading Comprehension}

It was hypothesized that decoding would not be as good a predictor of reading comprehension for children from low SES homes as it is for typically developing children from middle or high SES backgrounds. This was because of research showing that when children are able to decode well, the majority are equally able to comprehend what they read (Cain \& Oakhill, 2007; Catts \& Kamhi, 2005). Given this population, and the likely deficits in language, it was determined that the link between decoding and reading comprehension would not be as strong as it is for children from middle and high SES backgrounds and as a result, decoding would not be as strong a predictor of reading comprehension.

Results from this study show that the participants achieved similar scores on the Word Identification and Word Attack subtests of the WRMT-R, when compared to the standardization sample, while the average score on Passage Comprehension was below the expected mean. Specifically, all children except two earned standard scores at or above 85 on both of the decoding tests. These results may be explained by the regular literacy and specific decoding instruction in formal schooling. As a result of adequate and intensive decoding instruction the children were able to perform within the typical range on decoding tasks (Vellutino et al., 1996). Neuman (2006) pointed out that literacy instruction involves repetition, recall, and reciting in the primary grades and that this is typical throughout the United States. Specifically, most available and popular reading programs focus on code-related reading instruction that includes phonics and phonological awareness (Pearson \& Hiebert, 2010). The curriculum in the Knox county 
schools has an emphasis on decoding instruction and it seems clear that this instruction is effective.

In order to move from learning to read to reading to learn, children need to acquire more sophisticated language and world knowledge. Specifically, children from low SES backgrounds who have a limited language learning environment must acquire new vocabulary, world knowledge, and comprehension strategies through school instruction. Unfortunately, most reading comprehension programs available in the schools seem to pay little attention to these skills (Allington \& McGill-Franzen, 2009; Dewitz, Jones, \& Leahy, 2009; McGill-Franzen \& Allington, 1990; Walsh, 2003). Without the adequate and intensive instruction required for areas beyond decoding, children from low SES homes are unlikely to achieve at the same level as their middle to high SES peers. This is because the middle and high SES peers have had adequate opportunities within their home environment to acquire the language and world knowledge needed for successful reading comprehension. As a result, the absence of instruction focused on the known prerequisites to reading comprehension leads to a skill discrepancy for children from low SES backgrounds.

In summary, children raised in poverty are able to decode at the same level as their peers as result of formal schooling while they still lag behind in reading comprehension. The absence of focused reading comprehension instruction makes it far more likely that there will be an expanding language and knowledge gap, leading to a breakdown in reading comprehension (Barajas et al., 2008; Neuman, 2006).

\section{The Relationship between Reading Comprehension, Language and Decoding Skills}

This study found positive correlations between reading comprehension and decoding and language skills. Regression analyses showed that both decoding and language scores accounted for significant independent variance in reading comprehension beyond either decoding or language alone. Participants in this study did not demonstrate decoding problems although they did show lower receptive vocabulary, receptive and expressive language, and knowledge of story structure, and syntactic complexity skills. As a result, their poor performance on passage comprehension may be attributed to poor language skills.

According to the Simple View of Reading (Gough \& Tunmer, 1986; Hoover \& Gough, 1990), reading comprehension is comprised of decoding and language comprehension skills. Neither component is sufficient for reading, but rather both are necessary for successful reading comprehension. According to the model supporting the 'Simple View of Reading', there are three subgroups of children with reading comprehension problems: children with poor decoding skills but normal language skills, children with poor language skills but normal decoding skills, and children with both poor decoding and poor language skills. Children in this study appear to belong to the 'poor comprehender' group that includes children with poor language skills but normal decoding skills. 
Given the likelihood of limited to exposure to language and literacy in the home environment, it is probable that the children in this study were able to decode words and passages as a result of receiving regular instruction. With adequate decoding, the lack of linguistic and world knowledge appears to be the cause of their reading comprehension problems. However, research has shown that there is a reciprocal relationship between linguistic knowledge and reading comprehension. Reading skills also influence language skills and children acquire linguistic and world knowledge through reading activities (Nation, Cocksey, Taylor, \& Bishop, 2010). Children who read more books are more likely to improve their language skills as well as their reading. Conversely, children who do not read are less likely to build vocabulary, complex syntactic skills, and world and subject area knowledge. As a result, poor reading comprehension skills in this population also may lead to poor language skills.

Based upon study results, the characteristics of language, decoding, and reading comprehension abilities of children from low SES backgrounds are quite similar to those of children with poor reading comprehension due to psycholinguistic processing deficits. Research has reported that children who display reading comprehension problems with no decoding problems are likely to show mild to moderate language impairment with weaknesses in vocabulary, semantic processing, grammatical understanding, inference and narrative skills (Cain et al., 2004; Catts et al., 2006; Nation et al., 2004, 2010; Nation \& Snowling, 1999). In the current study, children from low SES background scored well below the standardization samples on receptive vocabulary, receptive and expressive language, knowledge of story structure, and syntactic complexity. These findings are consistent with previous studies documenting that children tend to have reading comprehension problems when they have weakness in language, even though the origin of reading failure may differ between children from low SES backgrounds and children with language impairment due to psycholinguistic problems.

Results also showed that when the language scores of the participants in this study were entered first into the regression analysis, language skill accounted for 63.2 percent of the total variance in passage comprehension. This finding provides a much higher percentage of the variance for passage comprehension when compared to previous studies. The study conducted by Keenan, Betjeman, and Olson (2008) investigated the relationship between passage comprehension, decoding skills and language skills for students ages 8 to 18 years. In their study, listening comprehension was entered first, and explained 29.1 percent of the variance for the Passage Comprehension subtest of the Woodcock-Johnson Tests of Achievement-III (WJTC-III; Woodcock, McGrew, \& Mather, 2001). Both passage comprehension subtests of the WJTC-III and WRMT-R use a cloze format that requires a student to fill in the blank using an appropriate word after reading a short sentence or passage. Even though the study by Keenan et al. (2008) had a broad age range and included older students, it does not influence the interpretation of the current study because the language proportion of the total variance for reading comprehension increases with age while the proportion of the variance in reading comprehension related to decoding decreases with age. 
Additionally, previous studies have reported that the cloze format of reading comprehension tests depend upon decoding skills rather than language skills (Catts et al., 2006; Cutting \& Scarborough, 2006; Keenan et al., 2008). If another reading comprehension test format that requires complex and integrated language skills was used, children who are characterized by average decoding and low language skills may show additional decreases in reading comprehension scores.

Results from this study support the hypothesis that decoding is not as good a predictor of reading comprehension for children from low SES backgrounds as it is for typically developing children from middle SES backgrounds, although decoding remains an important component of reading comprehension. In other words, for children from low SES backgrounds, the relationship between decoding and reading comprehension is relatively weak, while the relationship between language and reading comprehension is strong.

\section{Cognitive Skills and Reading Comprehension}

Based upon studies that show that children from low SES backgrounds may have difficulty with IQ tests because they lack experience with similar learning and assessment materials (Bradley \& Corwyn, 2002; NICHD, 2005), it was hypothesized that processing dependent measures (working memory) would be more predictive of reading comprehension than nonverbal IQ testing.

The results showed that the study participants scored below the mean on the TONI-3, a standardized nonverbal intelligence test, even though their performance fell within one standard deviation of the standardized mean. This result is consistent with previous studies that investigated the relationship between poverty and cognitive development (Barajas et al., 2008; Bradley \& Corwyn, 2002; Molfese et al., 2003; Najman et al., 2009; Smith, Brooks-Gunn, \& Klebanov, 1997). Research has shown that a negative relationship between poverty and cognitive development may emerge at 2 years (Barajas et al., 2008). This negative association between poverty and cognitive test scores may be an accumulative effect of poverty. Cognitive tests are also known to rely heavily on prior knowledge or experience. Children who are reared in poverty may not receive age-appropriate cognitive stimulation. The lack of learning opportunities in the home tends plays a negative role in cognitive development.

The children in this study did not differ from other approximately aged-matched groups on the Nonword Repetition Task as reported in previous studies. The groups that were compared to the participants in this study were typically developing children. This result supports the previous finding that processing-dependent measures do not rely upon prior knowledge and experience (Dollaghan et al., 1997). In other words, when children from low SES backgrounds process newly acquired information, they do not differ from children from middle to high SES backgrounds because they do not have a deficiency in psycholinguistic processing. Furthermore, this result is consistent with previous research that shows that children who have deficits in reading comprehension with adequate 
decoding skills do not demonstrate deficits on phonological working memory tasks such as the NRT or word and digit span tasks (Cain, 2006; Catts et al., 2006; Nation et al., 1999; Nation et al., 2004).

In contrast to the NRT results, study participants did not perform as well as children in previous studies on the Competing Language Processing Task (CLPT). This task is designed to measure the working memory capacity and activation for language processing while holding previous information in storage (Gaulin \& Campbell, 1994). Although both the NRT and CLPT investigate processing abilities, it has been shown that the CLPT relies more heavily on language processing. The word recall task of the CLPT requires the participant to process the meaning of a sentence while holding previous information in memory. Given the evidence that verbal working memory is mediated by semantic processing skills, it is not surprising that the children showed poorer performance on the CLPT (Nation et al., 1999). For children who display reading comprehension problems with adequate decoding skills, verbal working memory tasks such as the CLPT should have a strong relationship with language and reading comprehension (Daneman \& Carpenter, 1983; Gaulin \& Campbell, 1994; Montgomery, 2009; Weismer, Evans, \& Hesketh, 1999). Specifically, these children are likely to show inefficient processing skills when they have been given tasks that tap simultaneous storage and processing of verbal information (Cain et al., 2004; Cain, 2006; Nation et al., 1999; Pimperton \& Nation, 2009). Findings from the current study supports the evidence that children who show weakness in language, regardless of the origin, demonstrate difficulties with verbal working memory which involves storage and processing at the same time.

The results from this study showed that all cognitive scores were significantly correlated with reading comprehension. Bivariate regression results also showed that all cognitive scores accounted for significant variance in reading comprehension. Specifically, the word recall task of the CLPT explained a much higher proportion of the variance in Passage Comprehension than the TONI-3 and the NRT. This result is consistent with previous findings that verbal working memory is associated with language and reading comprehension (Leather \& Henry, 1994; Swanson \& Howell, 2001). Both the CLPT and reading comprehension require efficient allocation of limited resources for storage and processing. In order words, the successful reader needs to integrate incoming information, retrieve prior knowledge, and monitor for the inferencing of missing information.

Even though nonverbal intelligence testing is designed to be language-free, prior experience with puzzles and problem-solving may influence the results of the nonverbal IQ test. It is very possible that because of limited prior experience, children in this study scored lower than children from the national standardization sample. Results of the working memory tests lead to the conclusion that children who show deficits in reading comprehension in the absence of decoding problems will not show difficulties with phonological working memory. However, they will show inefficient processing skills on tasks that tap the simultaneous storage and processing of verbal information. For this reason, the NRT, which is considered to be a cognitive processing dependent measure 
that does not depend on prior knowledge, may be a useful clinical tool for differentiating between language disorders and language differences due to poverty. 


\section{CHAPTER 5. CONCLUSION}

Based on the results of the language, nonverbal IQ, decoding and processing tests administered to children, it is recommended that a school-based speech-language pathologist focus on language intervention to improve reading comprehension for children who show language difficulty with no decoding problems.

From a practical perspective, these findings have clinical implications for assessment and intervention. First, the results of this study suggest that language interventions focusing on specific deficit areas should be implemented to decrease any language and world knowledge gaps between children from low SES homes and those from middle SES families. Specifically, children in this sample were more likely to show weakness in vocabulary knowledge, syntactic skills and narrative structure including integration and organization of the whole story. This is particularly important because of the role these areas play in bridging the gap between oral language and written language.

Second, based on the 'Simple View' model, children who may be at risk for reading comprehension failure, such as those in this study, should be administered comprehensive language, decoding and reading comprehension tests. Decoding, by itself, is not a sufficient assessment of reading comprehension. Knowledge of language plays a vital role in reading comprehension success. This is particularly critical as children get older. Even though the research suggests that five to ten percent of school-age children have reading comprehension problems in the absence of decoding problems, most children with reading comprehension problems alone are not identified (Nation et al., 2004, 2010).

Third, in this study, the participants did not show difficulty on the Nonword Reptition Task which is related to learning new words (Gathercole \& Baddeley, 1989; Gathercole, Willis, Emslie, \& Baddeley, 1992; Metsala, 1999). Given the evidence that the phonological working memory is a key marker of language impairment and that children from low SES backgrounds, or linguistically diverse groups do not show deficits on this task, the NRT appears to be a useful clinical tool for differentiating between children with language disorders and children with language differences due to limited exposure.

Finally, a subsequent study should be carried out to explore the use of a different reading comprehension test with a different test format. This is because the Passage Comprehension subtests of the Woodcock-Johnson used in this study rely heavily on decoding (Catts et al., 2006; Cutting \& Scarborough, 2006; Keenan et al., 2008). The use of a more 'comprehension' oriented assessment may demonstrate even more issues with language ability and highlight the relationship between language and reading comprehension more clearly with this population. 


\section{LIST OF REFERENCES}

Adams, J. L., \& Ramey, C. T. (1980). Structural aspects of maternal speech to infants reared in poverty. Child Development, 51, 1280-1284.

Allhusen, V., Belsky, J., Booth-LaForce, C., Bradley, R., Brownell, C. A., Burchinal, M. R., ... Weinraub, M. (2005). Duration and developmental timing of poverty and children's cognitive and social development from birth through third grade. Child Development, 76(4), 795-810.

Allington, R., \& McGill-Franzen, A. (2009). Comprehension difficulties among struggling readers. In S. Israel \& G. Duffy (Eds.), Handbook of research on reading comprehension (pp.551-568). New York, NY: Routledge.

Alloway, T. P., \& Alloway, R. G. (2010). Investigating the predictive roles of working memory and IQ in academic attainment. Journal of Experimental Child Psychology, 106, 20-29.

Baddeley, A. D. (1986). Working memory. Oxford: Oxford University Press.

Baddeley, A. D., Gathercole, S. E., \& Papagno, C. (1998). The phonological loop as a language learning device. Psychological Review, 105, 158-173.

Barajas, R. G., Philipsen, N., \& Brooks-Gunn, J. (2008). Cognitive and emotional outcomes for children in poverty. In R. Crane, \& T. Heaton (Eds.), Handbook of families and poverty, (pp.311-333).Thousand Oaks, CA: Sage Publications, Inc.

Barone, D. (2006). Narrowing the literacy gap: What works in high poverty schools. New York, NY: Guilford Press.

Bhattacharya, A. (2010). Children and adolescents from poverty and reading development: A research review. Reading and Writing Quarterly, 26, 115-139.

Botting, N., Simkin, Z., \& Conti-Ramsden, G. (2006). Associated reading skills in children with history of specific language impairment. Reading and Writing, 19(1), 77-98.

Bradley, R. H., \& Corwyn, R. F. (2002). Socioeconomic status and child development. Annual Review of Psychology, 53, 371-399.

Brooks-Gunn, J., \& Duncan, G. J. (1997). The effects of poverty on children. Future Child, 7(2), 55-71. 
Brooks-Gunns, J., Klebanov, P. K., \& Duncan G. J. (1996). Ethnic differences in children's intelligence test score: Roles of economic deprivation, home environment, and maternal characteristics. Society for Research in Child Development, 67(2), 396-408.

Brown, L., Sherbenou, R., \& Johnsen, S. (1997) Test of Nonverbal Intelligence (3rd ed). Austin, TX: Pro-Ed.

Burt, L., Holm, A., \& Dodd, B. (1999). Phonological awareness skills of 4-year-old British children: An assessment and developmental data. International Journal of Language and Communication Disorders, 34, 311-335.

Cain, K. (2006). Individual differences in children's memory and reading comprehension: An investigation of semantic and inhibitory deficits. Memory, 14(4), 553-569.

Cain, K. (2007). Syntactic awareness and reading ability: Is there any evidence for a special relationship? Applied Psycholinguistics, 28, 679-694.

Cain, K., \& Oakhill, J. V. (2006). Profiles of children with specific reading comprehension difficulties. British Journal of Educational Psychology, 76, 683696.

Cain, K., \& Oakhill, J. V. (2007). Children's comprehension problems in oral and written language: A cognitive perspective. New York, NY: Guilford.

Cain, K., Oakhill, J. V., \& Bryant, P. E. (2004). Children's reading comprehension ability: Concurrent prediction by working memory, verbal ability, and component skills. Journal of Educational Psychology, 96, 31-42.

Catts, H., Adolf, S. M., \& Ellis Weismer, S. (2006). Language deficits in poor comprehenders: A case for the simple view of reading. Journal of Speech, Language, and Hearing Research, 49, 278-293.

Catts, H., Bridges, M., Little, T., \& Tomblin, J. (2008). Reading achievement growth in children with language impairment. Journal of Speech, Language, and Hearing Research, 51, 1569-1579.

Catts, H., Fey, M., Tomblin, B., \& Zhang, X. (2002). A Longitudinal investigation of reading outcomes in children with language impairments. Journal of Speech, Language, and Hearing Research, 45, 1142-1157.

Catts, H., \& Kamhi, A. (2005). Language and reading disabilities. Boston, MA: Allyn and Bacon.

Clegg, J., \& Ginsborg, J. (2006). Language and social advantage. Chichester: Wiley. 
Cunningham, P. M. (2006). High-poverty schools that beat the odds. The Reading Teacher, 6(4), 382-385.

Cutting, L., \& Scarborough, H. (2006). Prediction of reading comprehension: Relative contributions of word recognition, language proficiency and other cognitive skills can depend on how comprehension is measured. Scientific Studies of Reading, 10(3), 277-299.

Daneman, M., \& Carpenter, P. (1983). Individual differences in integrating information between and within sentences. Journal of Experimental Psychology: Learning, Memory, and Cognition, 9(4), 561-584.

Deacon, S. H., \& Kirby, J. (2004). Morphological awareness: Just "more phonological"? The roles of morphological and phonological awareness in reading development. Applied Psycholinguistics, 25, 223-238.

Denton, K., West, J., \& Walston, J. (2003). Reading -Young children's achievement and classroom experiences. Washington, DC: U.S. Dept. of Education, NCES 2003070 .

Dewitz, P., Jones, J., \& Leahy, S. (2009). Comprehension strategy instruction in core reading programs. Reading Research Quarterly, 44(2), 102-126.

Dodd, B., \& Carr, A. (2003). Young children's letter-sound knowledge. Language, Speech, and Hearing Services in Schools, 34, 128-137.

Dollaghan, C. A., Campbell, T. F., Paradise, J. L., Feldman, H. M., Janosky, J. E., \& Pitcairn, D. (1999). Maternal education and measures of early speech and language. Journal of Speech, Language, and Hearing Research, 42, 1432-1443.

Duncan, L. G., Brooks-Gunn, J., \& Klebanov, P. (1994). Economic deprivation and early childhood development. Child Development, 65(2), 296-318.

Duncan, L. G., \& Seymour, P. H. K. (2000). Socio-economic differences in foundationlevel literacy. British Journal of Psychology, 91, 145-166.

Dunn, L., \& Dunn, D. (1981). Peabody Picture Vocabulary Test - R. Circle Pines, MN; American Guidance Service.

Dunn, L., \& Dunn, D. (1997). Peabody Picture Vocabulary Test - III. Circle Pines, MN; American Guidance Service.

Dunn, L., \& Dunn, D. (2007). Peabody Picture Vocabulary Test - IV. Bloomington, MN: Pearson Inc. 
Eamon, M. K. (2010) Social-demographic, school, neighborhood, and parenting influences on the academic achievement of Latino young adolescents. Journal of Youth and Adolescence, 34(2), 163-174.

Engel, P. M. J., Santos, F. H., \& Gathercole, S. E. (2008). Are working memory measures free of socioeconomic influence? Journal of Speech, Language, and Hearing Research, 51, 1580-1587.

Fazio, B., Naremore, R., \& Connell, P. (1996). Tracking children from poverty at risk for specific language impairment: A 3-year longitudinal study. Journal of Speech and Hearing Research, 39, 611-624.

Francis, D., Shaywitz, S., Stuebing, K., Shaywitz, B., \& Flecher, J. (1996). Developmental lag versus deficit models of reading disability: A longitudinal, individual growth curves analysis. Journal of Educational Psychology, 88(1), 317.

Gathercole, S. E., \& Baddeley, A. D. (1990). Phonological memory deficits in language disordered children: Is there a causal connection? Journal of Memory and Language, 29, 336-360.

Gathercole, S. E., Willis, C. S., Emslie, H., \& Baddeley, A. D. (1992). Phonological memory and vocabulary development during the early school years: A longitudinal study. Developmental Psychology, 28, 887-898.

Ginsborg, J. (2006). The effect of socio-economic status on children's language acquisition and use. In J. Clegg \& J. Ginsborg (Eds.), Language and social disadvantage (pp.9-27). Chichester: Wiley.

Goff, D., Pratt, C., \& Ong, B. (2005). The relations between children's reading comprehension, working memory, language skills and components of reading decoding in a normal sample. Reading and Writing: An Interdisciplinary Journal, $18,583-616$.

Gough, P., Hoover, W., \& Peterson, C. L. (1996). Some observation on the simple view of reading. In C. Cornoldi \& J. Oakhill (Eds.), Reading comprehension difficulties: Processes and interventions (pp.1-13). Mahwah, NJ: Erlbaum.

Gough, P., \& Tunmer, W. (1986). Decoding, reading, and reading disability. Remedial and Special Education, 17(1), 6-10.

Hackman, D. A., \& Farah, M. J. (2009). Socioeconomic status and the developing brain. Trends in Cognitive Sciences, 13, 65-73.

Hart, B., \& Risley, T. (1995). Meaningful differences in the everyday experiences of young American children. Baltimore, MD: Brookes. 
Hecht, S. A. (2001). Comparing the predictive validity of first grade teacher ratings and reading-related tests on third grade levels of reading skills in young children exposed to poverty. School Psychology Review, 30(1), 50-60.

Hecht, S. A., \& Greenfield, D. B. (2002). Explaining the predictive accuracy of teacher judgments of their students' reading achievement: The role of gender, classroom behavior, and emergent literacy skills in a longitudinal sample of children exposed to poverty. Reading and Writing: An Interdisciplinary Journal, 15, 789809.

Hoff-Ginsberg, E. (1991). Mother-child conversation in different social classes and communicative settings. Child Development, 62, 782-796.

Hoover, W., \& Gough, P. (1990). Simple view of reading. Reading and Writing, 2(2), 127-160.

Hooper, S. R., Burchinal, M. R., Roberts, J. E., Zeisel, S., \& Neebe, E. C. (1998). Social and family risk factors for infant development at one year: An application of the cumulative risk model. Journal of Applied Developmental Psychology, 19(1), 8596.

Horton-Ikard, R., \& Weismer, S. E. (2007). A preliminary examination of vocabulary and word learning in African American toddlers from middle and low socioeconomic status homes. American Journal of Speech-Language Pathology, 16, 381-392.

Just, L. M., \& Carpenter, P. (1992). A capacity theory of comprehension: Individual differences in working memory. Psychological Review, 99, 122-149.

Justice, L. M., \& Ezell, H. K. (2001). Print referencing: An emergent literacy enhancement strategy and its clinical applications. Language, Speech, and Hearing Services in Schools, 35, 185-193.

Kamhi, A. (2007). Knowledge deficits: The true crisis in education. The ASHA Leader, 12(7), 28-29.

Keenan, K., Betjemann, R., \& Olson, R. (2008). Reading comprehension tests vary in the skills they assess: Differential dependence on decoding and oral comprehension. Scientific Studies of Reading, 12(3), 281-300.

Korenman, S., Miller, J., \& Sjaastad, J. (1995). Long-term poverty and child development in the child development in the United States: Results from the NLSY. Children and Youth Services Review, 17, 127-155.

Laing, S. P., \& Kamhi, A. (2003). Alternative assessment of language and literacy in culturally and linguistically diverse populations. Language, Speech, and Hearing Services in Schools, 34, 44-55. 
Leonard, L. B. (1998). Children with specific language impairment. Cambridge, MA: MIT Press.

Lester, H. (1986). A porcupine named fluffy. Boston, MA: Houghton Mifflin.

Lester, H. (1987). Pookins gets her way. Boston, MA: Houghton Mifflin.

Lether, C., \& Henry, L. (1994). Working memory span and phonological awareness tasks as predictors of early reading ability. Journal of Experimental Child Psychology, $58(1), 55-111$.

Locke, A., Ginsborg, J., \& Peers, I. (2002). Development and disadvantage: Implications for the early years and beyond. International Journal of Language \& Communication Disorders, 37(1), 3-15.

Lonigan, C. J., Bloomfield, B. G., Anthony, J. L., Bacon, K. D., Phillips, B. M., \& Samwel, C. S. (1999). Relations among emergent literacy skills, behavior problems, and social competence in preschool children from low- and middleincome backgrounds. Topics in Early Childhood Special Education, 19, 40-53.

Mayer, M., (1969). Frog, where are you? New York, NY: Dial.

McGill-Franzen, A., \& Allington, R. (1990). Comprehension and coherence: Neglected elements of literacy instruction in remedial and resource room service. Journal of Reading, Writing, and Learning Disabilities International, 6(2), 149181.

Metsala, J. (1999). Young children's phonological awareness and nonword repetition as a function of vocabulary development. Journal of Educational Psychology, 91(1), 3-19.

Miller, J. F., \& Chapman, R. S. (2008). Systematic Analysis of Language Transcripts (Version 8) [Computer software]. Madison, WI: University of WisconsinMadison, Waisman Center, Language Analysis Laboratory.

Molfese, V. J., Modglin, A., \& Molfese, D. L. (2003). The role of environment in the development of reading skills: A longitudinal study of preschool and school-age measures. Journal of Learning Disabilities, 36(1), 59-67.

Montgomery, J. (2002). Understanding the language difficulties of children with specific language impairments: Does working memory matter? American Journal of Speech-Language Pathology, 11, 77-91.

Montgomery, J. (2009). Complex sentence comprehension and working memory in children with specific language impairment. Journal of Speech, Language, and Hearing Research, 52, 269-288. 
Muter, V., Hulme, C., Snowling, M. J., \& Stevenson, J. (2004). Phonemes, rimes, vocabulary, and grammatical skills as foundation of early reading development: Evidence from a longitudinal study. Developmental Psychology, 40, 665-681.

Myers, L., \& Botting, N. (2008). Literacy in the mainstream inner-city school: Its relationship to spoken language. Child Language Teaching and Therapy, 24(1), 95-114.

Nagy, W. E., Berninger, V. W., \& Abbott, R. C. (2006). Contributions of morphology beyond phonology to literacy outcomes of upper elementary and middle-school students. Journal of Educational Psychology, 98, 134-147.

Najman, J. M., Mohammad, R., Hayatbakhsh, M. D., Heron, M. A., Bor, W., O'Callaghan, M. J., \& Williams, G. M. (2009). The impact of episodic and chronic poverty on child cognitive development. Journal of Pediatrics, 154, 284289.

Nation, K., Adams, J., Bowyer-Grane, C., \& Snowling, M. (1999). Working memory deficits in poor comprehenders reflect underlying language impairments. Journal of Experimental Child Psychology, 73(2), 139-158.

Nation, K., Clarke, P., Marshall, C., \& Durand, M. (2004). Hidden language impairments in children: Parallels between poor reading comprehension and specific language impairment? Journal of Speech, Language, and Hearing Research, 47, 199-211.

Nation, K., Cocksey, J., Taylor, J., \& Bishop, D. (2010). A longitudinal investigation of early reading and language skills in children with poor reading comprehension. Journal of Child Psychology and Psychiatry. 51(9), 1031-1039.

Nation, K., \& Snowling, M. (1999). Developmental differences in sensitivity to semantic relations among good priming. Cognition, 70, B1-B13.

Neuman, S. B. (2006). $\mathrm{N}$ is for nonsensical. Educational Leadership, 64(4), 28-31.

Newman, S. B., \& Celano, D. (2001). Access to print in low-income and middle-income communities: An ecological study of four neighborhoods. Reading Research Quarterly, 36, 6-26.

Nippold, M., Hesketh, L., Duthie, J., \& Mansfield, T. (2005). Conversational versus expository discourse: A study of syntactic development in children, adolescents, and adults. Journal of Speech, Language, and Hearing Research, 48, 1048-1064.

Norbury, C. F., \& Bishop, D. V. M. (2003). Narrative skills of children with communication impairments. International Journal of Language and Communication Disorders, 38, 287-313. 
Oakhill, J., \& Cain, K., (2007). Introduction to comprehension development. In K. Cain, \& J. Oakhill (Eds.), Children's comprehension problems in oral and written language: A cognitive perspective (pp.3-40). New York, NY: Guilford Press.

Oakhill, J., Yuill, N., \& Parkin, A. (1986). On the nature of differences between skilled and less-skilled comprehenders. Journal of Research in Reading, 9, 80-91.

Ouellette, G. P. (2006). What's meaning got to do with it: The role of vocabulary in word reading and reading comprehension. Journal of Educational Psychology, 98, 554566.

Parrila, R., Kirby, J. R., \& McQuarrie, L. (2004). Articulation rate, naming speed, verbal short-term memory, and phonological awareness: Longitudinal predictors of early development? Scientific Studies of Reading, 8, 3-26.

Paul, R., Hernandez, R., Tayler, L., \& Johnson, K. (1996). Narrative development in late talkers: Early school age. Journal of Speech and Hearing Research, 39, 12951303.

Pearson, P., \& Hiebert, E. (2010). National reports in literacy: Building a scientific base for practice and policy. Educational Researcher, 39(4), 286-294.

Peterson, C. (1994). Narrative skills and social class. Canadian Journal of Education, 13(9), 251-269.

Pimperton, H., \& Nation, S. (2010). Suppressing irrelevant information from working memory: Evidence for domain-specific deficits in poor comprehenders. Journal of Memory and Language, 62, 380-391.

Pruitt, S. (2006). Grammatical morphology of children reared in poverty implications for specific language impairment. (Doctoral dissertation). Retrieved from http://etd.1su.edu/docs/available/etd-10302006-120056/. Accessed in June 1, 2011.

Pruitt, S., \& Oetting, J. (2009). Past tense marking by African American Englishspeaking children reared in poverty. Journal of Speech, Language, and Hearing Research, 52, 2-15.

Pruitt, S., Oetting, J., \& Hegarty, M. (2010). Passive participle marking by African American English-speaking children reared in poverty. Journal of Speech, Language, and Hearing Research, 54(2), 598-607.

Qi, C., Kaiser, A., Milan, S., \& Hancock, T. (2006). Language performance of lowincome African American and European American preschool children on the PPVT-III. Language, Speech, and Hearing Services in Schools, 37, 5-16. 
Reese, E., Suggate, S., Long, J., \& Schaughency, E. (2010). Children's oral narrative and reading skills in the first 3 years of reading instruction. Reading and Writing, 23, 627-644.

Roseberry-McKibbin, C. (2008). Increasing language skills of students from low income backgrounds. San Diego, CA: Plural Publishing.

Roth, F., Speece, D., \& Cooper, D. (2002). A longitudinal analysis of the connection between oral language and early reading. The Journal of Educational Research, 95(5), 259-272.

Sameroff, A. J., Seifer, R., Baldwin, A., \& Baldwin, C. (1993). Stability of intelligence from preschool to adolescence: The influence of social and family risk factors. Child Development, 64(1), 80-97.

Seigneuric, A., \& Ehrlich, M. F. (2005). Contribution of working memory capacity to children's reading comprehension: A longitudinal investigation Reading and Writing: An Interdisciplinary Journal, 18, 617-656.

Semel, E., Wiig, E., \& Secord, W. (2003). Clinical Evaluation of Language Fundamentals- IV. San Antonio, TX: The Psychological Corp.

Shankweiler, D., Lundquist, E., Katz, L., Stuebing, K. K., Fletcher, J. M. Brady, S., . . . Shaywitz, B. A. (1999). Comprehension and decoding: Patterns of association in children with reading difficulties. Scientific Studies of Reading, 3, 69-94.

Shiro, M. (2003). Genre and evaluation in narrative development. Journal of Child Language, 30, 165-195.

Sirin, S. R. (2005). Socioeconomic status and academic achievement: A meta-analytic review of research. Review of Educational Research, 75(3), 417-453.

Smith, J., Brooks-Gunn, J., \& Klebanov, P. (1997). Consequences of living in poverty for young children's cognitive and verbal ability and early school achievement. In G. Duncan \& J. Brooks-Gunn (Eds.), Consequences of growing up poor (pp.132189). New York, NY: Russell Sage Foundation.

Snyder, L., \& Downey, D. (1991). The language-reading relationship in normal and reading-disabled children. Journal of Speech and Hearing Research, 34, 129-140.

Stanton-Chapman, T. L., Chapman, D. A., Kaiser, A. P., \& Hancock, T. B. (2004). Cumulative risk and low-income children's language development. Topics in Early Childhood Special Education, 24(4), 227-237.

Steig, W. (1982). Doctor De Soto. New York, NY: Farrar, Straus and Giroux. 
Storch, S. A., \& Whitehurst, G. J. (2002). Oral language and code-related precursors to reading: Evidence from a longitudinal structural model. Developmental Psychology, 38(6), 934-947.

Swanson, H. (1999). Reading comprehension and working memory in learning-disabled readers: Is the phonological loop more important than the executive system? Journal of Experimental Child Psychology, 72(1), 1-31.

Swanson, H., \& Howell, M. (2001). Working memory, short-term memory, and speech rate as predictors of children's reading performance at different ages. Journal of Educational Psychology, 93(4), 720-734.

Terry, N. C., Connor, C. M., Thomas-Tate, H., \& Love, M. (2010). Examining relationships among dialect variation, literacy skills, and school context in first grade. Journal of Speech, Language, and Hearing Research, 53, 126-145.

Turkheimer, E., Haley, A., Waldron, M., D’Onofrio, B., \& Gottesman, I. I. (2003). Socioeconomic status modifies heritability of IQ in young children. Psychological Science, 14, 623-628.

van Kleeck, A. (2007). SLPs' foundational role in reading comprehension: A response to Alan Kamhi. The ASHA Leader, 12(10), 32-33.

Vasilyeva, M., Waterfall, H., \& Huttenlocher, J. (2008). Emergence of syntax: Commonalities and differences across children. Developmental Science, 11(1), 84-97.

Vellutino, F., Scanlon, D., Sipay, E., Small, S., Pratt, A., Chen, R., \& Denckla, M. (1996). Cognitive profiles of difficult-to remediate and readily remediated poor readers: Early intervention as a vehicle for distinguishing between cognitive and experiential deficits as basic causes of specific reading disability. Journal of Educational Psychology, 88(4), 601-638.

Walsh, K. (2003). Basal readers: The lost opportunity to build the knowledge that propels comprehension. American Educator, 27(1), 24-27.

Washington, J. (2001). Early literacy skills in African-American children: Research considerations. Learning Disabilities Research \& Practice, 16, 213-221.

Washington, J., \& Craig, H. (1999). Performance of at-risk, African American preschoolers on the Peabody Picture Vocabulary Test-III. Language, Speech, and Hearing Services in School, 30, 75-82.

Weismer, S., Evans, J., \& Hesketh, L. (1999). An examination of verbal working memory capacity in children with specific language impairment. Journal of Speech, Language, and Hearing Research, 42, 1249-1260. 
Westby, C. E. (1991). Learning to talk-talking to learn: Oral literate language differences. In C. Simon (Ed.), Communication skills and classroom success: Assessment and therapy methodologies for language and learning disabled students (pp.181-218). San Diego, CA: College-Hill.

Whitehurst, G. J. (1997). Language processes in context: Language learning in children reared in poverty. In L. B. Adamson \& M. A. Romski (Eds.), Communication and language acquisition: Discoveries from atypical development (pp.233-265). Baltimore, MD: Brookes.

Whitehurst, G. J., \& Fischel, J. E. (2000). A developmental model of reading and language impairments arising in conditions of economic poverty. In D. Bishop \& L. Leonard (Eds.), Speech and language impairments in children: Causes, characteristics, intervention and outcome (pp.53-71). East Sussex, England: Psychology Press.

Willows, D. M., \& Ryan, E. B. (1986). The development of grammatical sensitivity and its relationship to early reading achievement. Reading Research Quarterly, 21, 253-266.

Woodcock, R. (1987). Woodcock Reading Mastery Tests-revised. Circle Pines, MN: American Guidance Service.

Wulbert, M., Inglis, S., Kriegsman, E., \& Mills, B. (1975). Language delay and associated mother-child interaction . Developmental Psychology, 11, 61-70. 


\section{VITA}

Hyo Jin Yoon was born in Korea in 1976. She received her Bachelor's degree in French Language and Literature from Kangwon National University, Korea in 2000 and her Master's degree in Speech Pathology from Hallym University in Korea in 2004. Hyo Jin then decided to pursue her doctoral degree in Speech and Hearing Science at the University of Tennessee in August, 2006 and received her Doctor of Philosophy in 2011. She has had one peer reviewed journal publication, and 10 presentations at national conferences. 